\title{
REGIONAL DIVERSITY IN THE MURINE CORTICAL VASCULAR NETWORK IS REVEALED BY SYNCHROTRON X-RAY TOMOGRAPHY AND IS AMPLIFIED WITH AGE
}

\author{
J.A. Núñez ${ }^{1,2}$, A. Goring ${ }^{1}$, B. Javaheri ${ }^{3}$, H. Razi ${ }^{4}$, D. Gomez-Nicola ${ }^{1}$, E. Hesse ${ }^{5,6}$, A.A. Pitsillides ${ }^{3}$, P.J. Thurnerer, \\ P. Schneider ${ }^{2,}$ and C.E. Clarkin ${ }^{1, \$, *}$ \\ ${ }^{1}$ Biological Sciences, Faculty of Natural and Environmental Sciences, University of Southampton, SO17 1BJ, UK \\ ${ }^{2}$ Bioengineering Sciences Research Group, Faculty of Engineering and the Environment, \\ University of Southampton, SO17 1BJ, Southampton, UK \\ ${ }^{3}$ Department of Comparative Biomedical Sciences, Royal Veterinary College, NW1 0TU, London, UK \\ ${ }^{4}$ Max Planck Institute of Colloids and Interfaces, Department of Biomaterials, \\ Research 9 Campus Golm, 14424 Potsdam, Germany \\ ${ }^{5}$ Heisenberg-Group for Molecular Skeletal Biology, Department of Trauma, Hand and Reconstructive Surgery, \\ University Medical Centre Hamburg-Eppendorf, Hamburg, Germany \\ ${ }^{6}$ Department of Anatomy and Cell Biology, Indiana University School of Medicine, Indianapolis, IN, USA \\ ${ }^{7}$ Institute of Lightweight Design and Structural Biomechanics, Vienna University of Technology, \\ 1060 Vienna, Austria \\ $\S$ These authors contributed equally to this study
}

\begin{abstract}
Cortical bone is permeated by a system of pores, occupied by the blood supply and osteocytes. With ageing, bone mass reduction and disruption of the microstructure are associated with reduced vascular supply. Insight into the regulation of the blood supply to the bone could enhance the understanding of bone strength determinants and fracture healing. Using synchrotron radiation-based computed tomography, the distribution of vascular canals and osteocyte lacunae was assessed in murine cortical bone and the influence of age on these parameters was investigated. The tibiofibular junction from 15-week- and 10-month-old female C57BL/6J mice were imaged post-mortem. Vascular canals and three-dimensional spatial relationships between osteocyte lacunae and bone surfaces were computed for both age groups. At 15 weeks, the posterior region of the tibiofibular junction had a higher vascular canal volume density than the anterior, lateral and medial regions. Intracortical vascular networks in anterior and posterior regions were also different, with connectedness in the posterior higher than the anterior at 15 weeks. By 10 months, cortices were thinner, with cortical area fraction and vascular density reduced, but only in the posterior cortex. This provided the first evidence of age-related effects on murine bone porosity due to the location of the intracortical vasculature. Targeting the vasculature to modulate bone porosity could provide an effective way to treat degenerative bone diseases, such as osteoporosis.
\end{abstract}

Keywords: Bone, ageing, vasculature, endothelial cells, osteocytes, micro-computed tomography, synchrotron.

*Address for correspondence: Claire Clarkin, Department of Biological Sciences, University of Southampton, SO17 1BJ, Southampton, UK.

Email: C.E.Clarkin@soton.ac.uk

Copyright policy: This article is distributed in accordance with Creative Commons Attribution Licence (http://creativecommons.org/licenses/by-sa/4.0/).

\section{Introduction}

The understanding of the physiological mechanisms regulating vascular behaviour in aged bone is challenging due to the inaccessibility of the blood vessels, which are deeply encased within the adult bone tissue. Bone is highly vascularised and it is proposed that the vascular network might be an active mediator of skeletal adaptation (Jaffe, 1930). It is generally accepted that skeletal development and growth, bone modelling, remodelling and repair are entirely dependent upon direct interactions with the vascular supply (Carulli et al., 2013). Proximity to the bone vessels also influences bone cell survival (Ham, 
1952) and reduction of the blood supply induces a consequent decrease of bone-forming activity (Carulli et al., 2013). Additionally, blood vessels are present in bone remodelling units and it is hypothesised that the vasculature has a role in coordinating coupling between osteoclasts and osteoblasts (Parfitt, 2000).

Bone-forming osteoblasts are the predominant source of pro-angiogenic vascular endothelial growth factor (VEGF) within the bone (Clarkin et al., 2008) and a reciprocal paracrine relationship between osteoblasts and endothelial cells exists during fracture repair (Hu and Olsen, 2016). Accumulating evidence suggests that age affects VEGF production and blood vessel growth (Kreisle et al., 1990; Reed et al., 2017; Shimada et al., 2004). Also, age-related changes are reported during bone repair ( $\mathrm{Lu}$ et al., 2006). In addition, age affects vascularisation during fracture healing and is directly correlated to a reduction in the expression of angiogenic factors, such as VEGF (Lu et al., 2006). The importance of the relationship between bone tissue and the vascular system is highlighted pathologically, whereas modifications in blood supply and reduced number of arterial capillaries in the bone marrow associate with bone loss (Alagiakrishnan et al., 2003; Burkhardt et al., 1987; Reeve et al., 1988).

Cortical bone has an interconnected network of vascular canals that comprise the living space of the vasculature (Havers, 1691). This network provides conduits for the blood supply in the bone cortex and, ultimately, acts to sustain osteocyte viability (Bonewald, 2011). The canals can either be incorporated into the bone during growth as primary canals (Maggiano, 2012) or, in larger vertebrates, can be the products of tissue turnover and are referred to as secondary canals (Frost, 1963). Concentric layers of bone - structures known as Haversian canals - surround the secondary canals. With ageing, increased cortical porosity is observed in humans, which is thought to be linked to increases in Haversian canal diameter (Burr, 2010). In mice, secondary modelling does not take place (as there is no Haversian canal system); however, vascular canals are present (Cooper et al., 2016) but the effects of age on murine cortical porosity remain unclear.

Cortical bone accounts for $80 \%$ of the mass of bone (Burr, 2010), significantly contributing to bone strength, while being structurally more important than trabecular bone at some skeletal sites (Holzer et al., 2009; Mazess, 1990). The loss of cortical rather than trabecular bone predominates in some types of fractures (Ferretti et al., 1995). Indeed, cortical bone loss accounts for $70 \%$ of all age-related appendicular bone loss (Zebaze and Seeman, 2015). However, it remains unclear whether alterations in the endothelial cells lining the intracortical vasculature specifically occur with age, whether they can influence agerelated bone loss and to what extent preservation of the cortical vasculature could prevent bone fractures.

In the past, imaging of the bone vasculature has been problematic, due to the nature of the skeletal tissue itself and efforts have been focused on inferring the three-dimensional (3D) structure of the vascular network within the bone. Histology has been the "gold standard" for years, used in both clinical diagnosis and biomedical research (Weibel, 1989). However, histology requires special sample preparation, including embedding, sectioning (most frequently preceded by decalcification) and staining; in addition, it is also destructive and two-dimensional (2D). On the other hand, bone specimens can be evaluated in 3D and non-destructively by X-ray micro-computed tomography $(\mu \mathrm{CT})$, which does not require special sample preparation. Standard $\mu \mathrm{CT}$ or X-ray absorption-based $\mu \mathrm{CT}$ essentially map the local X-ray attenuation of the specimen in 3D at a $\mu \mathrm{m}$ resolution (Feldkamp, 1989). Although conventional absorption-based $\mu \mathrm{CT}$ is not sensitive enough to provide sufficient contrast for soft tissues, such as the vasculature, it is used to provide spatial clues for the location of the blood vessels that reside within the intracortical canal network (Schneider et al., 2009). The intracortical canal network can be extracted as a negative imprint of the calcified tissue from standard $\mu C T$ images and several studies apply this principle to human (Cooper et al., 2003; Cooper et al., 2007a; Cooper et al., 2007b) and rodent bones (Britz et al., 2010; Britz et al., 2012; Schneider et al., 2007; Schneider et al., 2013; Thurner et al., 2010). Imaging of osteocytes in bone has also proved problematic in the past, due to the mineralisation of the bone matrix. Recent efforts focus on detecting the non-mineralised spaces, or osteocyte lacunae, wherein the osteocyte cells reside and large-scale $\mu \mathrm{CT}$ analyses at the tissue level are carried out to detect and quantify the morphology of the osteocyte lacunae in 3D (Dong et al., 2014; Mader et al., 2013; Palacio-Mancheno et al., 2014; Tommasini et al., 2012). The capabilities of standard $\mu \mathrm{CT}$, based on a lab-based X-ray source, can be significantly extended when synchrotron sources (SR) are used as the actual X-ray source (Schneider et al., 2009). In this case, high spatial resolutions in the order of $1 \mu \mathrm{m}$ can be achieved, within a few minutes at excellent signal-to-noise ratios, to resolve intracortical microstructures, such as the intracortical network or osteocyte lacunae (Dong et al., 2014; Mader et al., 2013; Schneider et al., 2007; Schneider et al., 2013) - instead of up to a day (or even longer) when using a standard lab-based X-ray source (Feldkamp, 1989).

Driven by the hypothesis that the intracortical vasculature is modified with age in mice, highresolution synchrotron-computed tomography (SR-CT) was utilised to assess the 3D distribution of vascular canals and osteocyte lacunae and quantify their spatial relationship with age. Herein, age-related and regional differences in the intracortical vascular canals and their spatial interactions with osteocyte lacunae were described. The results of this study provided the first evidence that intracortical vascular structures were distinct within specific regions of the murine cortex and that these differences were amplified with age. New therapeutic approaches 


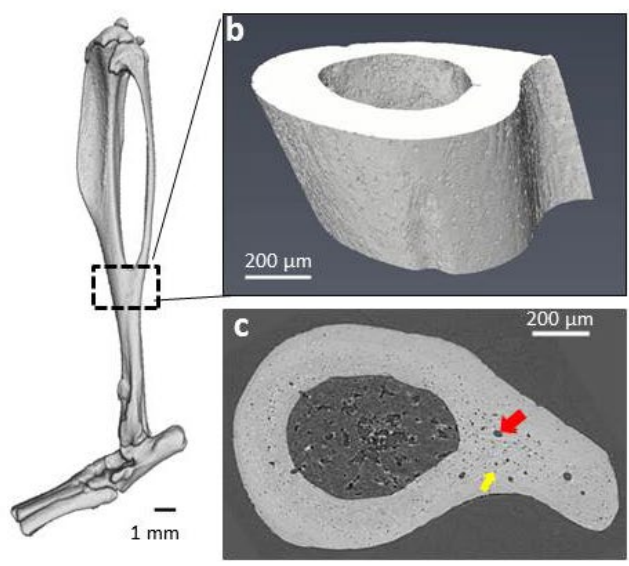

d

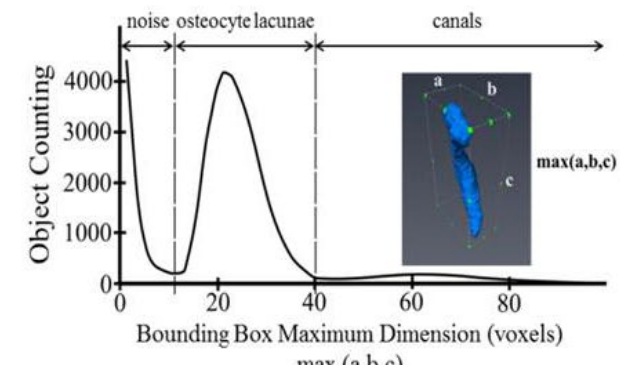
$\max (a, b, c)$

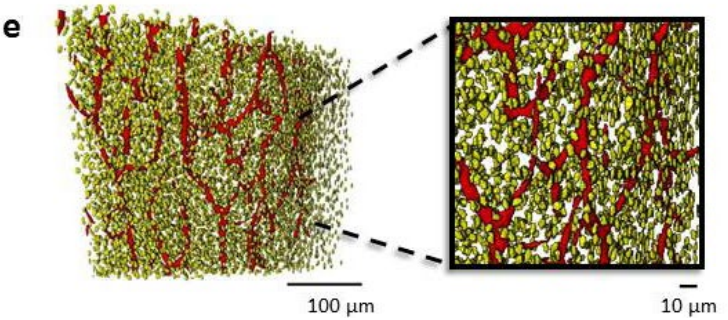

Fig. 1. Murine tibia, scanned region of interest and intracortical porosity separation using SRCT. (a) $\mu \mathrm{CT}$ image of an entire murine tibia and location of the tibiofibular junction with (b) magnified scanned region, using SR-CT. (c) One reconstructed SR-CT slice with red outlined arrow pointing to a vascular canal and yellow solid arrow pointing to an osteocyte lacuna. (d) Classification criteria for the porosity objects was demonstrated by a histogram of the maximum dimension of the bounding box for all porosity objects with noise/ canaliculi-lacunae and lacunae-canals limits; a, $\mathrm{b}$ and $\mathrm{c}$ are the dimensions of the bounding box. (e) 3D rendering of vascular canals (red) and osteocyte lacunae (yellow) with magnified region. Data were assessed at a voxel size of $0.65 \mu \mathrm{m}$.

retaining vascular health in cortical bone could improve current osteoporotic treatment options, preventing bone loss in addition to improving osteoporotic fracture healing.

\section{Materials and Methods}

\section{Animals}

Mice and surgical procedures were handled according to the guidelines of the Animals (Scientific
Procedures) Act, 1986. The murine bones were obtained in compliance with the EU Directive 2010/63/EU and the approval of the Animal Welfare and Ethical Review Board of the University of Southampton, UK. 15-week- $(n=6)$ and 10-monthold $(n=6)$ C57BL/6 female mice (Charles River Laboratories) were euthanised by cervical dislocation. 15-week-old mice were chosen as they are considered to be adults, with mineral and organic bone content reaching a steady state (Somerville et al., 2004). They were compared with 10-month-old animals, which present age-related skeletal changes (Halloran et al., 2002). The left and right tibiae were harvested, cleaned of soft tissue, fixed for $48 \mathrm{~h}$ in $4 \%$ paraformaldehyde ( $\mathrm{pH}$ 7.4) on a rotation stage at $4{ }^{\circ} \mathrm{C}$ and preserved thereafter in $70 \%$ ethanol prior to $\mathrm{CT}$ imaging and histology. Right tibiae were used for CT imaging and contralateral left tibiae for histological analysis.

\section{SR-CT imaging}

Right tibiae were embedded in paraffin wax to prevent sample movement during CT scans. The bones were scanned using SR-CT at the TOMCAT beamline of the Swiss Light Source (Villigen, Switzerland) at a voxel size of $0.65 \mu \mathrm{m}$. For each scan, 3,001 projection images were acquired over a range of $360^{\circ}$, at a photon energy of $18.5 \mathrm{keV}$ and exposure time of $180 \mathrm{~ms}$, corrected for ring artefacts due to potential scintillator defects, and reconstructed using standard filtered back-projection. Fig. 1a shows a 3D representation of a murine tibia, with the scanned region highlighted and magnified (Fig. 1b). Scans were centred at the tibiofibular junction (maximum outer dimension of $1.5 \mathrm{~mm}$ ) within a lateral field of view of $3.3 \mathrm{~mm}$, which was achieved by scanning over an angular range of $360^{\circ}$ (instead of only $180^{\circ}$ ) and by stitching projections to double the field of view laterally (i.e. perpendicular to the rotation axis). SRCT datasets consisted of a stack of 1,000 reconstructed SR-CT slices, corresponding to a vertical field of view of $0.65 \mathrm{~mm}$. The tibiofibular junction was chosen as the region of interest for scanning, as it provides a clear landmark for SR-CT data evaluation, allowing for consistency in the analysed region across animals (Brommage et al., 2014; Campbell and Sophocleous, 2014; Holguin et al., 2016; Javaheri et al., 2015; Warner et al., 2006). Furthermore, at this anatomical site, trabecular bone is absent and only cortical bone was assessed. Fig. 1c shows one SR-CT slice with marked vascular canals and osteocyte lacunae.

\section{Image processing and analysis}

SR-CT datasets were processed and analysed using the commercial software Avizo 9 (FEI, Hillsboro, OR, USA), Matlab R2014 (MathWorks, MA, Natick, USA) and freeware ImageJ (Schneider et al., 2012). Image processing involved the segmentation of mineralised bone tissue, the extraction of the bone porosity or intracortical microstructure (i.e. vascular canals and osteocyte lacunae at the present spatial resolution), the separation of osteocyte lacunae from 


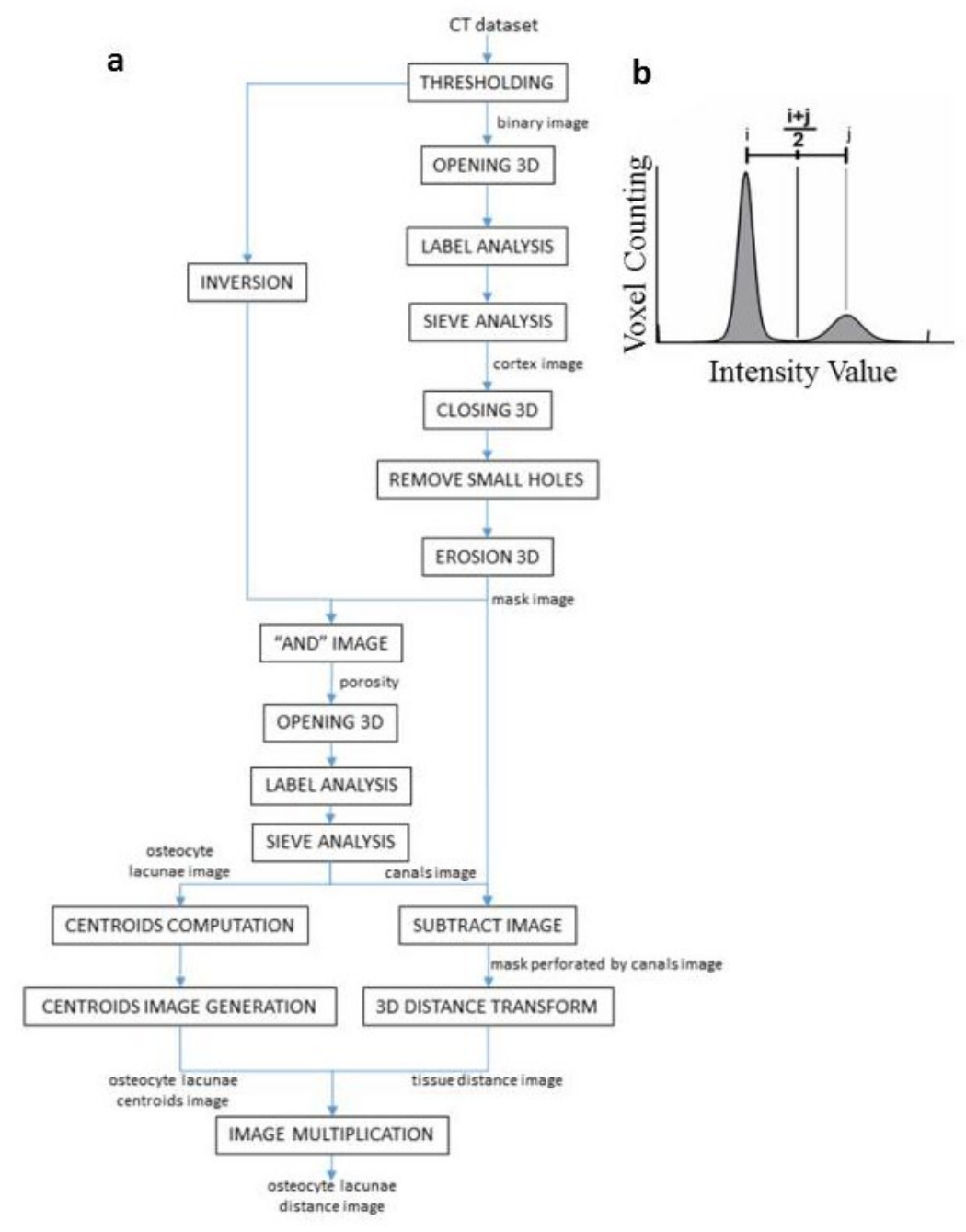

Fig. 2. (a) Image processing and analysis workflow. CT datasets were binarised by global thresholding to capture the mineralised tissue. Porosity was extracted and classified into canals and osteocyte lacunae combining the binarised image with the cortical mask (solid cortex without pores). 3D distance-transform computed the distances to the nearest bone surface (including canals) to produce a 3D tissue distance image. Then, the tissue distance image was combined with the location of the osteocyte lacunae (defined by their centroids) to generate the osteocyte lacunae distance image. (b) 3D bimodal histogram and intermodes global thresholding for image segmentation that used the midpoint between the two peaks ( $i$ and $j$ ) as the threshold value.

vascular canals (Fig. 1d,e) and the creation of distance maps for the computation of distances between the different microstructures. Fig. 2 summarises the image processing workflow adopted.

The first step was the segmentation of the mineralised tissue. The bimodal 3D image histogram was thresholded using the "intermodes global" method in ImageJ (Fig. 2b). Global thresholding is an image segmentation method that replaces a pixel in a greyscale image with a black pixel if the image intensity is less than some fixed constant (the threshold) or a white pixel if the image intensity is greater than that constant. The "intermodes global" thresholding identifies the values of the two histogram peaks ( $i$ and $j$ in Fig. 2 b) and uses the midpoint as threshold. The output of the thresholding operation is a binary image (image composed of two intensity values only, namely object and background).

After the thresholding operation, to improve accuracy in the segmentation, a series of operations were performed to remove some clusters of pixels that should have been part of the background of the image and were incorrectly identified as mineralised tissue. This second step, namely the cleaning, starts with a "3D opening" operation followed by a component "labelling" with the individual components detected sorted by volume in Avizo 9. The labelled image was then sieved, to keep only the largest component (cortical bone) in Avizo 9 and all the clusters of pixels that were incorrectly included as mineralised tissue were removed.

The following group of operations were performed to generate an image of the solid cortex (mask). A "3D closing" operation (Avizo 9) incorporated the osteocyte lacunae that were detected as part of the background because of their proximity to the bone surfaces. Subsequently, cortical pores were removed with an operation that filled all the holes smaller than a fixed value (determined by the size of the medullary cavity; Avizo 9). A "3D erosion" operation (Avizo 9) thinned the solid cortical image to ensure that the final mask image was within the actual mineralised cortex.

In order to extract cortical porosity, the thresholded data (binary image produced in the first step of the process) were inverted and combined with the mask in an "and" logical operation (Avizo 9), resulting in a dataset containing the pores. A "3D opening" operation was applied (Avizo 9) to separate clusters of pores. The separated pores were sorted by component "labelling" and a bounding box was computed for each pore (Avizo 9). The maximum dimension of 
each bounding box (Fig. 1d) was used to classify the particles into noise, osteocyte lacunae and canals using maximum dimension criteria. Fig. 1e shows a 3D rendering of the vascular canals and osteocyte lacunae after the classification operation. The canal spaces were removed from the initial mask to create a further mask perforated by canals. This was done by combining the mask and canal images in a "subtraction" operation (Avizo 9). The "3D distance transformation" in ImageJ was used to compute proximity to a bone surface, including intracortical vascular surfaces (Fig. 3a), for every voxel within the perforated mask. Fig. $3 \mathbf{b}$ shows the colour mapping of the computed distances on sectioned cortical tissue. This tissue distance image was used, with the location of the osteocytes defined by their centroids, to generate osteocyte distance to closest surface images with a multiplication operation (ImageJ). The spatial coordinates $(X, Y, Z)$ of the centroids were computed in Avizo 9 by running a component labelling on the osteocyte lacunae image. The centroids' spatial
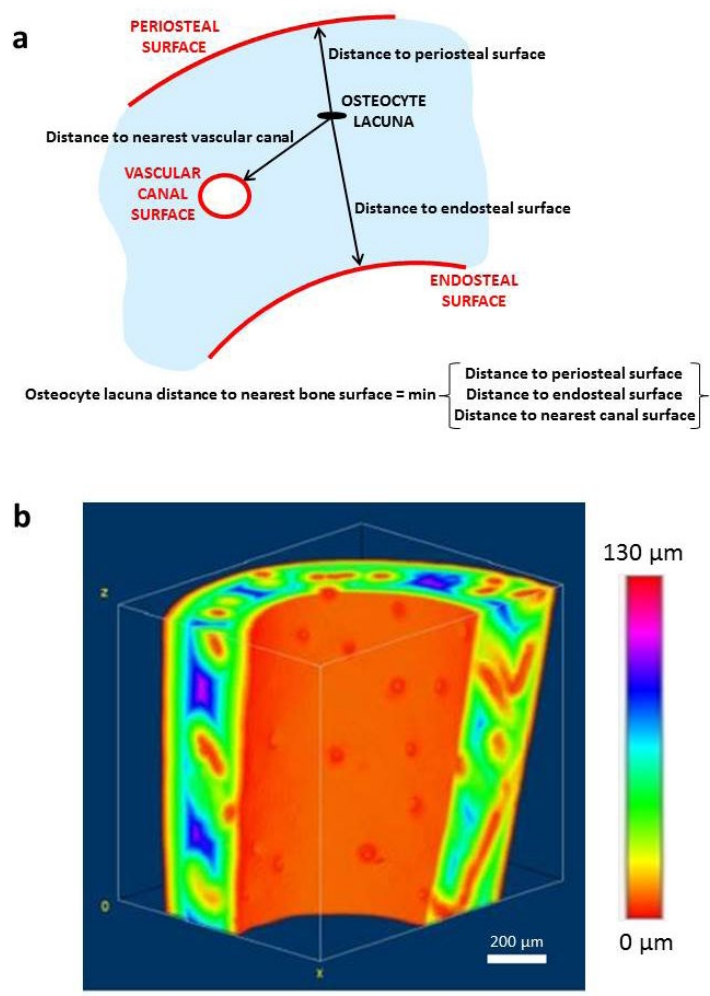

Fig. 3. Distance of osteocyte lacunae to nearest bone surface. (a) Identification of bone surfaces and distances for an osteocyte lacuna, where osteocyte lacuna distance to nearest bone surface is defined as the minimum of the distances to periosteal, endosteal and canal surfaces. (b) 3D distance transform colour mapped on the mineralised tissue sectioned by a longitudinal cut of the tibial cortex, where different colours represent varying distances to the nearest intracortical canal or bone surface. coordinates were processed in Matlab (in-house script) to generate the 3D centroids image. In particular, osteocytes and canals were separated based on the size of their maximal bounding box dimension, with a lower limit of 10 pixels or $6.5 \mu \mathrm{m}$ for osteocyte lacunae and a lower limit of 40 pixels or $26 \mu \mathrm{m}$ for canals. Reported dimensions of osteocyte lacunae in adult (femoral) murine bone (assuming an ellipsoidal lacuna model) range roughly between 5-10 $\mu \mathrm{m}$ (height and width) and 15-20 $\mu \mathrm{m}$ (Mader et al., 2013). Consequently, a lower limit of $6.5 \mu \mathrm{m}$ for the maximal bounding box for osteocyte lacunae separated them well from noise and a lower limit of $26 \mu \mathrm{m}$ for the maximal bounding box distinguished canals from osteocyte lacunae, where numbers for mean canal lengths above $50 \mu \mathrm{m}$ are reported for adult (femoral) murine bone (Schneider et al., 2017; Schneider et al., 2013). Canaliculi interconnecting osteocyte lacunae, which represent an intracortical microstructure at a smaller length scale with typical lateral dimensions in the order of $100 \mathrm{~nm}$ (You et al.,

a

Osteocyte Lacunar Distance Distribution

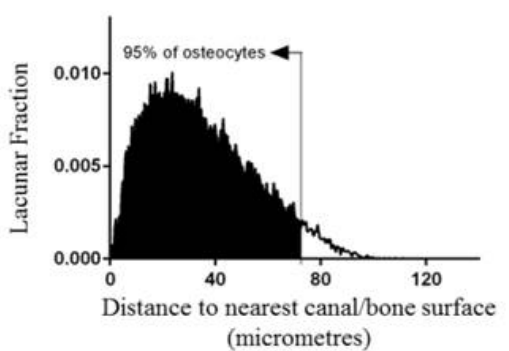

b

Cumulative Osteocyte Lacunar Distance Distribution

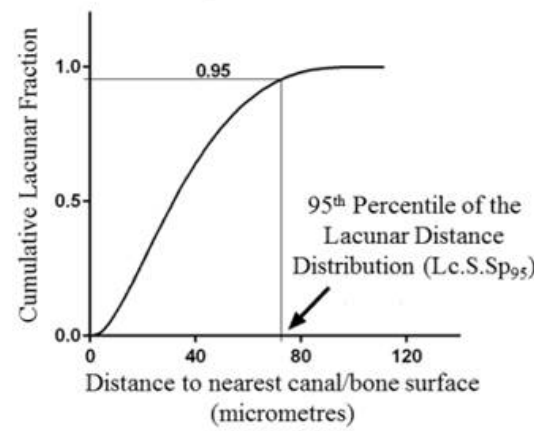

c

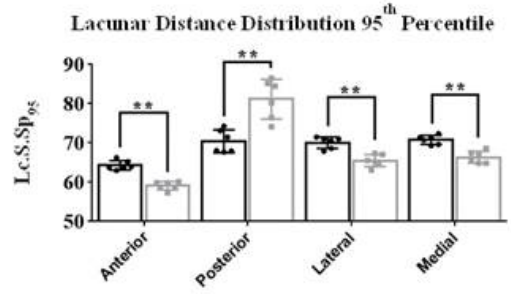

Fig. 4. (a) Osteocyte lacunar distance distribution and $(\mathbf{b})$ cumulative distribution with definition of $95^{\text {th }}$ percentile and (c) quantification in localised regions of the tibiofibular junction. Error bars indicate mean value $\pm \mathrm{SD}, n=6$ biological replicates for both age groups. ${ }^{* *} p<0.001$. 
Table 1. Effect of the exclusion of intracortical canals in tissue distances to nearest canal/bone surface for young animals. Morphometric measure indicates mean value $\pm \mathrm{SD}, n=6$ biological replicates.

\begin{tabular}{|c|c|c|c|c|}
\hline Parameter & $\begin{array}{c}\text { Intracortical canals } \\
\text { included }\end{array}$ & $\begin{array}{c}\text { Intracortical canals } \\
\text { excluded }\end{array}$ & Difference (\%) & U test $(p)$ \\
\hline $\begin{array}{c}\text { Max tissue distance to } \\
\text { bone surface }(\mu \mathrm{m})\end{array}$ & $117.285 \pm 5.785$ & $191.180 \pm 8.421$ & 63.005 & 0.0313 \\
\hline
\end{tabular}

a Bone Volume Density

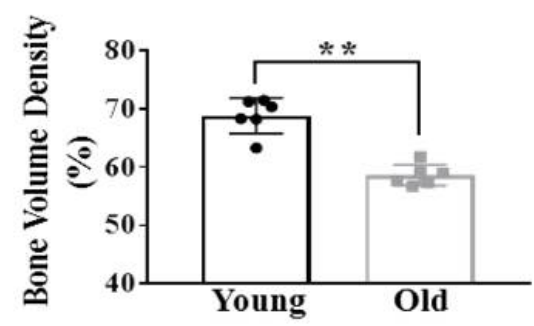

C

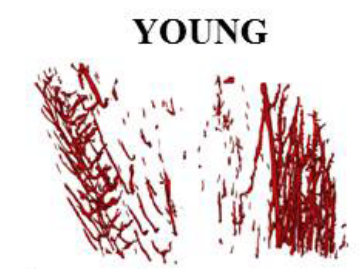

$\overline{500 \mu \mathrm{m}}$

OLD

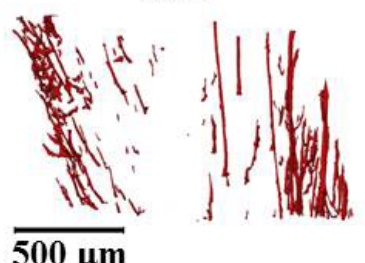

f

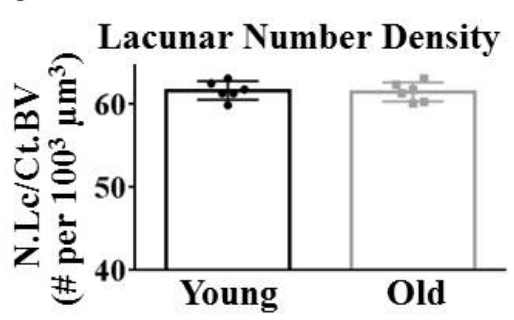

b

Cortical Thickness

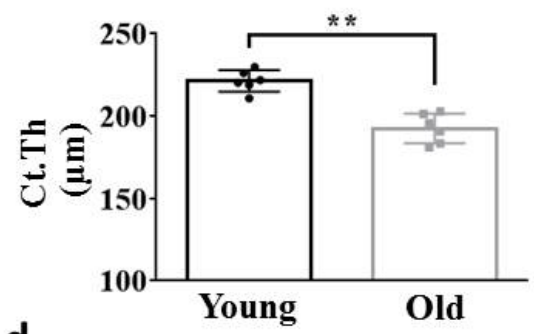

d

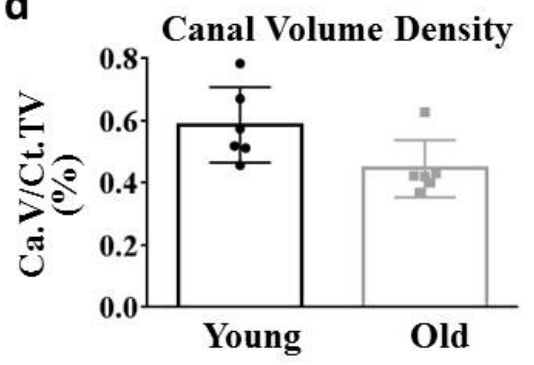

e

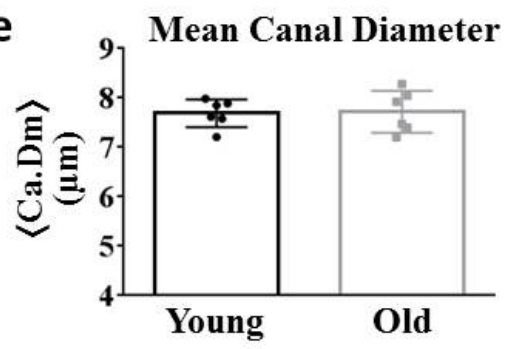

g

Lacunar Distance Distribution

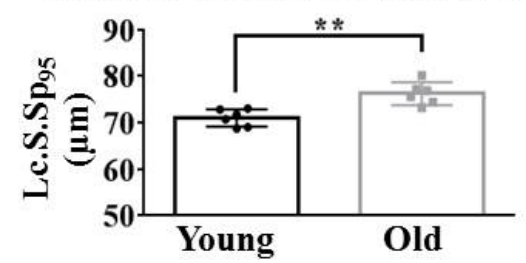

Fig. 5. Effects of age on bone and vascular parameters in the undivided tibiofibular junction. Average (a) cortical area fraction, (b) cortical thickness, (c) 3D renderings of the intracortical vascular canals in a young and old mouse, (d) canal volume density, (e) mean canal diameter, (f) osteocyte lacunar number density and $95^{\text {th }}$ percentile of $(\mathrm{g})$ lacunar distance distribution to nearest bone surface. Error bars indicate mean value $\pm S D$, $n=6$ biological replicates for both age groups. ${ }^{* *} p<0.001$.
2004; Goggin et al., 2016), could not be resolved using SR-CT.

Quantification of cortical vascular canals, following quantitative morphometric measures introduced for osteocyte lacunae and canal network (Schneider et al., 2007), correspond to standard nomenclature for bone morphometry (Bouxsein et al., 2010; Parfitt et al., 1987). This includes canal volume density (Ca.V/Ct.TV), which was computed by calculating the canal volume (Ca.V) and dividing it by the total volume of the cortical bone compartment (Ct. TV), or the (solid) cortical mask. Mean canal diameter
( $(\mathrm{Ca}$.Dm $\rangle)$ was calculated using the "thickness" command of the ImageJ plugin BoneJ (Doube et al., 2015), which follows the method by Hildebrand and Rüegsegger (1997) to assess thickness in 3D. Canal connectedness (Ca.Co) was defined as the inverse of the number of the biggest canal structures accounting for $80 \%$ of the canal volume (Ca.V), which is 1 for a simply connected vascular network and decreases for an increasing number of disconnected canals that make up the bulk of the canal volume. This measure is insensitive to the influence of small canals and characterises the connectedness 
of the bulk of the canal network (only). It is an indicator for characterising the dis-connectivity of the intracortical canals based on the number of individual disconnected structures comprising the canal volume. The number of canals (N.Ca) or the normalised measured canal number density (N.Ca/ Ct.TV) were not included in the current analyses, as they were not representative of the actual number of intracortical canals present since some disconnected vascular segments were observed. If included, this would represent an inaccurate quantification of the number of canals. It is the authors' opinion that it was more appropriate to quantify the connectedness of the vascular network by introducing the canal connectedness (Ca.Co) and to report on canal volume density (Ca.V/Ct.TV), where the latter was not biased.

\section{Quantification of osteocyte lacunae}

Lacuna number density (N.Lc/Ct.TV) was computed by dividing the number of osteocyte lacunae (N.Lc) by the total volume of the cortical bone (Ct.TV).

The computed distances of the osteocyte lacunae to the nearest bone surfaces (periosteal, endosteal or intracortical vascular canal; Fig. 3a) were converted into distributions (Fig. 4). Mean (〈Lc.S.Sp $\rangle)$ and $95^{\text {th }}$ percentile (Lc.S.Sp $\left.{ }_{95}\right)$ of the osteocyte lacunar distance distribution were used as indicators for the 3D spatial relationships between vasculature and osteocyte lacunae (Fig. 4). 〈Lc.S.Sp〉 indicates the average distance of all studied osteocyte lacunae from their nearest bone surface, where the brackets denote the average over all elements following the convention introduced by Schneider et al. (2007). On the other hand, Lc.S.Sp $\mathrm{P}_{95}$ represents a robust measure of the farthest distance from the nearest bone surface that was calculated for $95 \%$ of all examined osteocyte lacunae. The $5 \%$ most extreme osteocyte lacunae, exhibiting the largest distances from the nearest bone surface, were intentionally excluded to guarantee a robust measure that was independent of the outliers. The effect of excluding intracortical canals in tissue distances to bone surfaces is summarised in Table 1 . A colour-coded 3D distance transform was mapped on the mineralised cortical tissue, which was virtually sectioned by a longitudinal cut of the tibial cortex (Fig. 3b), representing varying distances to the nearest bone surface by different colours.

\section{Quantification of cortical bone}

The cross-sectional cortical bone area of the cortex was computed at the height of the tibiofibular junction on the binarised image of the solid cortex (mask; 1 slice per dataset). Cortical area fraction was computed as the ratio between the cross-sectional cortical bone area and the total cross-sectional area inside the periosteal envelope (including the medullary cavity). The average outer diameter was computed from the total cross-sectional area using the a

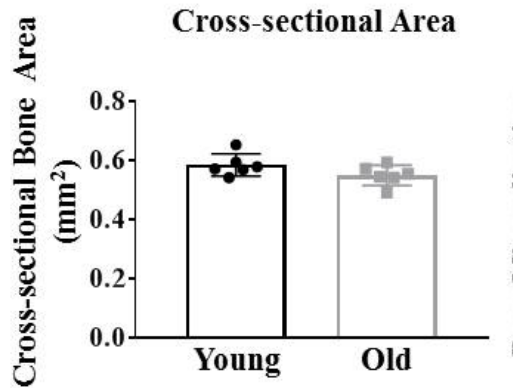

C

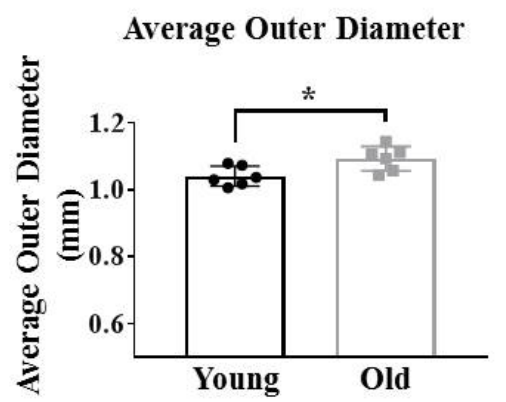

b

Bone Mineralisation

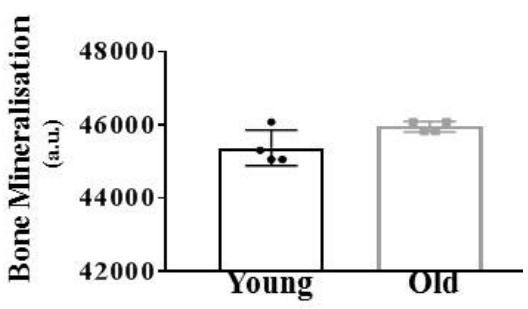

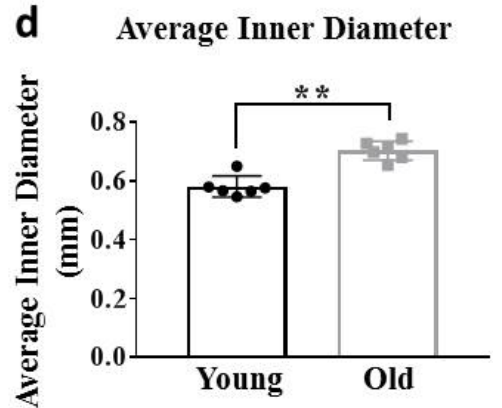
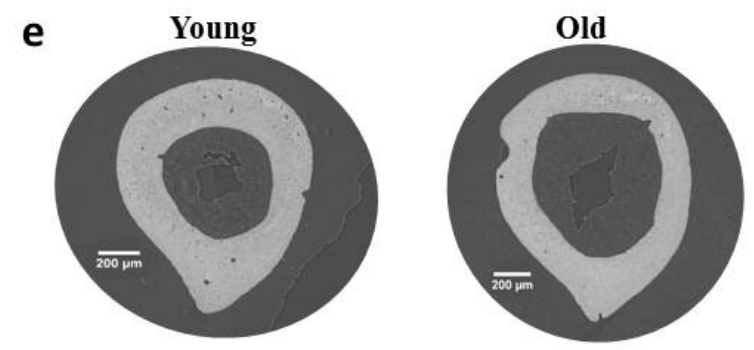

Fig. 6. Age-related changes in cortical bone geometry and mineralisation. (a) Cross-sectional cortical bone area, (b) bone mineralisation, (c) average outer diameter and (d) average inner diameter for young and old mice. (e) Reconstructed CT slices for a young and old mouse. Error bars indicate mean value $\pm \mathrm{SD}, n=6$ biological replicates for both age groups. ${ }^{*} p<0.05,{ }^{* *} p<0.001$. 
Table 2. Global morphometric measures for young and old animals $(\mu \mathrm{CT})$. Morphometric measures indicate mean value $\pm \mathrm{SD}, n=6$ biological replicates. Bone mineralisation is presented as arbitary units (a.u.) and cortical thickness (Ct.Th). Other indices are listed in the legend for Table 1.

\begin{tabular}{|c|c|c|c|c|}
\hline Parameter & 15 weeks (young) & 10 months (old) & Difference (\%) & $\mathrm{U}$ test $(p)$ \\
\hline Ct.Th $(\mu \mathrm{m})$ & $221.380 \pm 5.956$ & $192.510 \pm 9.065$ & -13.041 & 0.002 \\
\hline Ca.V/Ct.TV (\%) & $0.585 \pm 0.111$ & $0.444 \pm 0.092$ & -24.076 & 0.056 \\
\hline$\langle$ Ca.Dm $\rangle(\mu \mathrm{m})$ & $7.103 \pm 0.621$ & $7.261 \pm 1.033$ & 2.232 & 0.898 \\
\hline $\begin{array}{l}\text { N.La/Ct.TV } \\
\left(\text { per } 100 \mu \mathrm{m}^{3}\right)\end{array}$ & $61.566 \pm 1.011$ & $61.391 \pm 1.153$ & -0.285 & 0.898 \\
\hline Lc.S.Sp ${ }_{95}(\mu \mathrm{m})$ & $71.025 \pm 1.857$ & $76.246 \pm 2.427$ & 7.351 & 0.002 \\
\hline$\langle$ Lc.S.Sp $\rangle(\mu \mathrm{m})$ & $34.264 \pm 0.866$ & $35.284 \pm 0.706$ & 2.978 & 0.093 \\
\hline $\begin{array}{c}\text { Cross-sectional bone area } \\
\left(\mathrm{mm}^{2}\right)\end{array}$ & $0.585 \pm 0.037$ & $0.550 \pm 0.034$ & -6.053 & 0.240 \\
\hline Cortical area fraction $(\%)$ & $68.799 \pm 3.048$ & $58.607 \pm 1.792$ & -14.814 & 0.002 \\
\hline Average outer diameter (mm) & $1.040 \pm 0.093$ & $1.093 \pm 0.037$ & 5.006 & 0.026 \\
\hline Average inner diameter (mm) & $0.581 \pm 0.361$ & $0.703 \pm 0.0324$ & 21.031 & 0.002 \\
\hline Bone mineralisation (a.u.) & $45375 \pm 485$ & $45951 \pm 148$ & 1.3 & 0.171 \\
\hline
\end{tabular}

formula for the area of the circle. The same approach was used to determine the average inner diameter (or average diameter of the medullary cavity), using the cross-sectional area derived from the binarised image of the medullary cavity (mask) and the formula for the circle.

Local measurements of the cortical thickness were performed at the height of the tibiofibular junction, for 1 slice per dataset, using mask images for 4 different cortical regions (anterior, medial, posterior, lateral; Fig. 9a) and the "straight" function on ImageJ, which provides a measurement of the linear distance.

Bone mineralisation was assessed from the SRCT data. The measure used was the location of the mineralised segment/phase within the histogram of the grey values of the SR-CT images, representing the linear (X-ray) attenuation coefficient. Using the bimodal histogram of the 3D CT datasets, the position of the mineralised tissue peak was determined and compared for 8 datasets ( $n=4$ mice per age group).

\section{Histology}

One of the limitations to SR-CT is related to the challenge of visualising the soft tissue, comprising the blood vessels, within the canals and the osteocyte cells within the lacunae. Standard X-ray absorptionbased imaging only provides low contrast for soft tissues, which absorb hard X-rays to a very limited extent (Nunez et al., 2017). Therefore, histology was used to assess canal and osteocyte lacunae occupancy.
Contralateral left tibiae were dissected free of soft tissues. Dehydration was carried out by immersing the tissue in a series of increasing concentrations of EtOH solutions until $100 \%$ was reached and the tissue could be infiltrated with polymethylmethacrylate (PMMA). Bone cutters (Fine Science Tools, Foster City, CA, USA) were used for sectioning just above the tibiofibular junction and cutting the upper region of the tibia off. Following dehydration, bones were soaked for $24 \mathrm{~h}$ at $4{ }^{\circ} \mathrm{C}$ in PMMA. PMMA blocks were ground down using a grinder-polisher (MetaServ 250, Buehler, IL, USA) so that the cut surface was flat. $10 \mu \mathrm{m}$-thick sections were cut out from the proximal end using a microtome (Leica Biosystems, Wetzlar, Germany) to trim the bone, until the tibiofibular junction was reached. $5 \mu \mathrm{m}$-thick sections were cut and one drop of $80 \%$ isopropanol solution added to each section to prevent folding. Sections were placed in an incubator at $37^{\circ} \mathrm{C}$ overnight, to dry the tissue, and stained with either pentachrome or Giemsa staining, to visualise endothelial cells. For the quantification of canal occupancy by blood vessels, 2 pentachrome stained sections of each tibiofibular junction from 3 animals of each age group were examined, with each section containing the entire cortical ring. Quantification of osteocyte lacunae occupancy was carried out in 3 animals from each age group using one entire pentachrome-stained crosssection of cortical bone, created from multiple images using AutoStitch (University of British Columbia, 


\section{a}

Exclusion of Intracortical Canals Effect on Tissue Distances

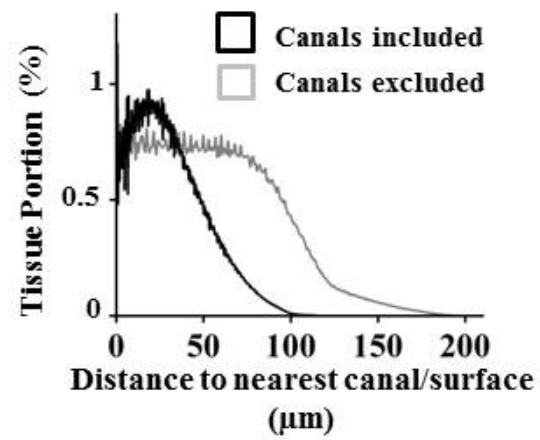

\section{Exclusion of Intracortical Canals Effect on Max. Tissue Distances}

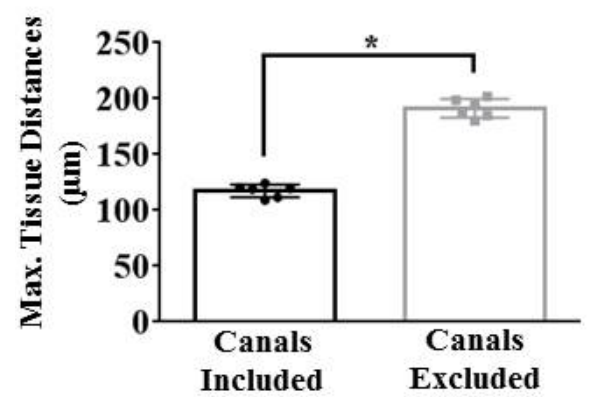

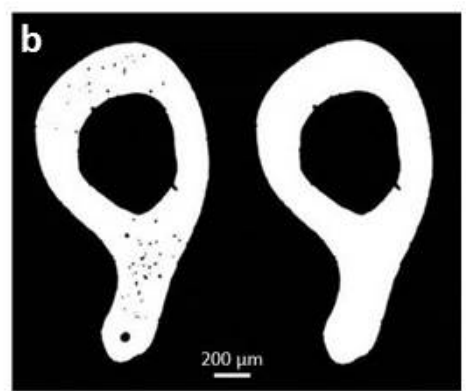
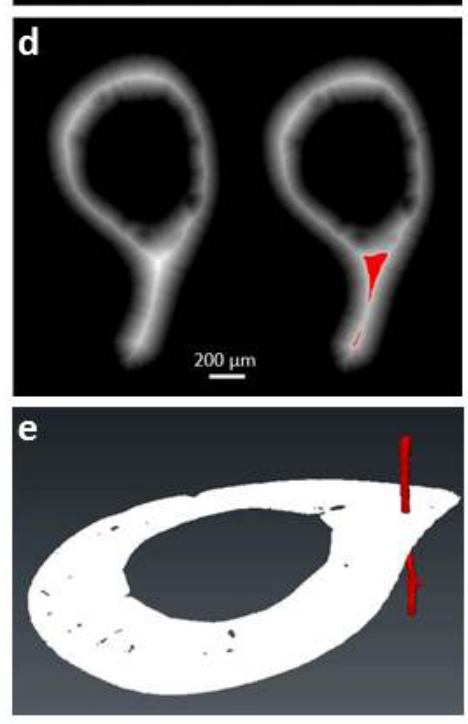

Fig. 7. Tissue distance distribution to nearest bone surface in the presence and absence of intracortical canals. (a) Effect of exclusion of intracortical canals on osteocyte distance to nearest canal/bone surface. (b) Binarised cross-section with intracortical canals (left) and excluded canals (right). (c) Comparison of maximum distance distribution. (d) 2D slice of $3 \mathrm{D}$ distance transform on mask (left) and identification of altered distance in the posterior region in red colour (right). (e) 3D position of main blood vessel canal present in the posterior region.
Vancouver, Canada). The "cell counter" function on ImageJ was used to quantify canal structures, vessels, osteocytes and osteocyte lacunae within the histological sections.

\section{Finite element analysis}

Local tibia strains were characterised by finite element modelling (FEM). A FEM of the entire tibia of a 15-week-old mouse was created in Abaqus 6.14-5 software (Dessault Systemes Simulia Corp., Providence, RI, USA). Initially, a tibia was scanned using Skyscan 1172 (Skyscan, Kontich, Belgium), with X-ray tube at $50 \mathrm{kV}$ and $200 \mu \mathrm{A}, 1,600 \mathrm{~ms}$ exposure time and $5 \mu \mathrm{m}$ voxel size. Slices were reconstructed using NRecon1.6 (Bruker, Billerica, MA, USA) and images were used to develop the models. Briefly, $\mu \mathrm{CT}$ images were segmented to bone and non-bone regions based on the entire bone CT histogram (global threshold was set at $35 \%$ of max linear attenuation coefficient). Then, the segmented bone surfaces were discretised and filled with multi-resolution volumetric linear tetrahedral mesh elements $(\approx 1.2 \mathrm{e} 6$ elements). Pre-processing and meshing of the $\mu \mathrm{CT}$ data were performed using ZIBAmira software (Zuse Institute, Berlin, Germany).

FEM boundary conditions were set to replicate an axial compression loading within the mouse tibia. Axial compression in hind limbs creates a strain environment similar to that generated during habitual daily activity (Wehner et al., 2010). Consistent with previous reports (Razi et al., 2015), bone orientation with respect to load axis was secured by defining longitudinal (proximal-distal axis, P-D) and medio-lateral (M-L) tibial axes, using anatomical landmarks, and the bone was aligned accordingly. Pressure surfaces at the knee and ankle were selected to assign load and boundary conditions. These surfaces were based on previous studies on human cadavers at flexed knees. Load contact surface at the distal tibia (ankle joint) was fixed in all degrees of freedom and load contact surface at proximal tibia (knee joint) was restrained from off-axis movement from loading axis. Load $(11 \mathrm{~N})$ was inserted at the proximal tibia contact surface. To isolate the effect of morphology, a homogeneous material property was assigned [Young's modulus: $17 \mathrm{GPa}$ and Poisson's ratio: 0.3 (Razi et al., 2015)]. Total strain and stress components were calculated for each element in the model and absolute maximum principal strain (representing largest absolute maximum, tensile and minimum, compressive, principal strain value) was reported at the bone cross section at the level of the tibiofibular junction.

\section{Statistical analysis}

To analyse the effect of age on the undivided tibiofibular junction, non-parametric Mann-Whitney tests were used to provide for more robust analysis, given the relative small sample sizes $(n=6$ biological replicates per group). The effect of the interaction between location within the cortex and age was evaluated by a two-way ANOVA (due to the lack of 

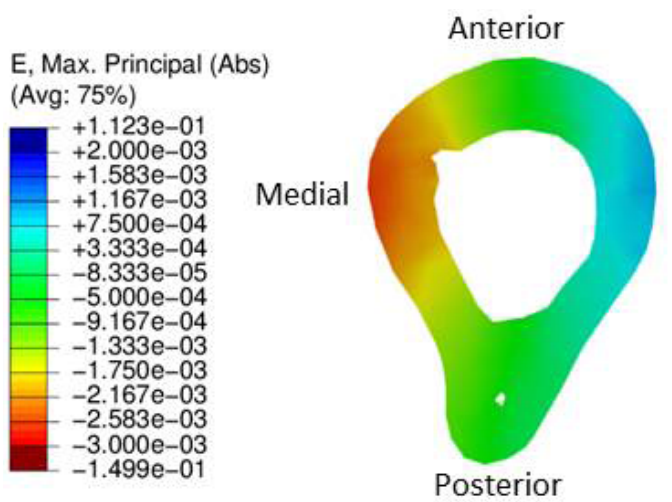

Lateral

Fig. 8. Strain distribution at the bone cross section of a 15-week-old mouse at the tibiofibular junction calculated by FEM. Statistically significant differences in compressive versus tensile strain were calculated.

a reasonable non-parametric alternative) combined with non-parametric post-hoc tests. To preserve statistical power, the number of comparisons between groups were restricted to the effect of age evaluated by Mann-Whitney test and the effect of location (cortical regions) within the cortex by Wilcoxon matched-pairs signed rank test. All statistics were performed using GraphPad Prism version 6.0 for Windows (GraphPad Software, La Jolla, CA, USA). Data were expressed as mean \pm standard deviation (SD).

\section{Results}

\section{Vascular canal volume density was not modified} in undivided cortex of aged murine cortical bone High-resolution scans of the tibiofibular junction region of 15-week- and 10-month-old C57BL/6 mice showed that older mice had a significantly reduced cortical area fraction (Fig. 5a) and thinner cortices as compared to 15 -week-old animals $(-13 \%$, $p=0.002$; Fig. 5b). Cross-sectional cortical area did not change with age (Fig. 6a); however, the average outer diameter of the cortex and the average inner cortex diameter increased significantly with age (Fig. 6c-e). Bone mineralisation measurements were unchanged between groups (Fig. $6 \mathbf{b}$ and Table 2) and no significant age-related changes were found for overall canal volume density ( $p=0.056$; Fig. $5 d$ d), mean canal diameter ( $p=0.898$; Fig. $5 \mathbf{e})$. In addition, no significant differences between age groups were identified in measurements of lacuna number density ( $p=0.898$; Fig. $6 \mathbf{f}$ ) or mean of lacunar distance distribution ( $p=0.093$; Fig. $6 \mathrm{~g}$ ), when the entire tibiofibular junction region was analysed; however, $95^{\text {th }}$ percentile of the lacunar distance distribution was found to increase in older animals $(7.35 \%, p=0.002)$ within the posterior region, which motivated the local analysis of the tibiofibular cortex.

\section{Osteocyte distribution analysis revealed intracortical canals in the posterior region that could support osteocyte survival}

Most of the osteocyte lacunae were positioned within $\approx 40 \mu \mathrm{m}$ from the nearest bone surface in young cortical bone, with $\approx 120 \mu \mathrm{m}$ being the largest distance measured (Fig. 7a). When intracortical canals were excluded from the analyses (Fig. 7a,b), the distance to the nearest surface for a population of $12 \%$ of total osteocyte lacunae increased to $\approx 120$ $190 \mu \mathrm{m}$ (Fig. 7a,c). Evaluation of the distribution of the osteocyte lacunae in this region showed that they were located exclusively in the posterior region of the cortex (Fig. 7d) - which was the same region where the $95^{\text {th }}$ percentile of the lacunar distance distribution increased with age, while it decreased for all other regions (Fig. 4c). To better understand this result, the main vascular canal in the posterior region was reconstructed (Fig. 7e). Following FE analysis, inhomogeneous regions of high mechanical strain were identified, with peak compressive strains in the medial region and peak tensile strains at the lateral regions, although this difference was not significant. The anterior and posterior regions had lower overall strain levels and compressive principal strains appeared to dominate in these regions (Fig. 8).

\section{Diversity in vascular canals within the tibiofibular cortex was amplified with age}

Following the identification of vascular canals that were intimately linked to the distribution of the osteocytes in young cortical bone, their precise location and organisation was analysed by subdividing this region into 4 regions or quadrants (Fig. 9a). Lateral and medial regions had significantly lower canal volume density and reduced diameter in comparison with the anterior and posterior regions (Fig. $9 \mathbf{b}-\mathbf{d}$ and Table 3). Upon separation, the vascular networks of the posterior region appeared structurally distinct to those of the anterior region. Specifically, canal volume density in the posterior region was significantly higher than in the anterior region ( $p=0.031$; Fig. $9 \mathrm{c})$ and no regional differences were found for mean canal diameter $(p=0.495$; Fig. $9 d)$. Furthermore, in the posterior region, blood vessels were better interconnected than in the anterior region $(p=0.031$; Table 4$)$. Lacuna number density was similar in the 4 regions $(p=0.194$; Fig. 9e). Together, these data suggested that intracortical vasculature was heterogeneously distributed within the tibiofibular cortex and it might be differentially regulated by regional cues.

Regional reduction in cortical thickness due to ageing was evident in all regions (Fig. 10a). To evaluate whether age exerted differential effects on the local distribution of intracortical vascular canals, the vascularised anterior and posterior regions were compared. No significant age-related variations in canal volume density in the anterior region were observed ( $p=0.474$; Fig. 10c and Table 5); however, the posterior region exhibited a significant reduction 


\section{a}

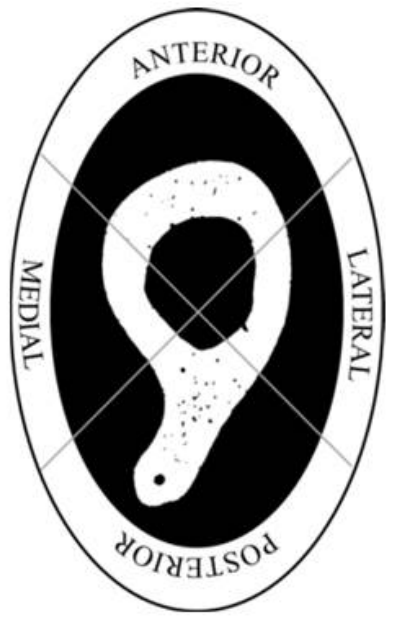

C

Canal Volume Density

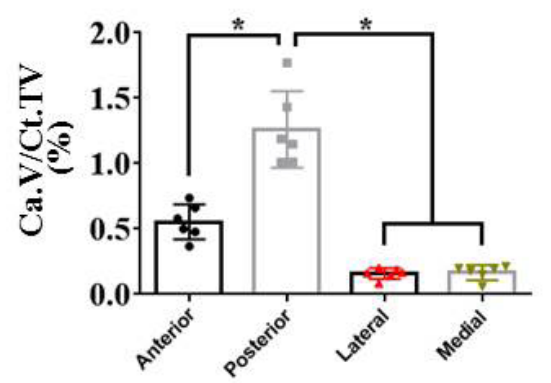

b

MEDIAL

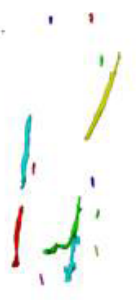

(i)

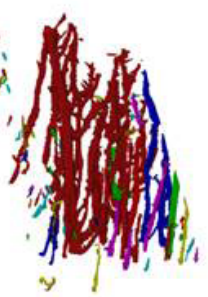

POSTERIOR

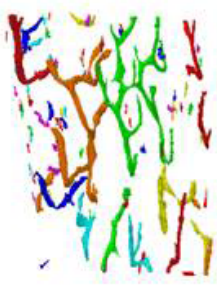

ANTERIOR

LATERAL

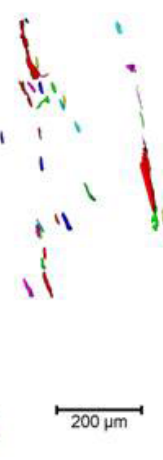

$\overrightarrow{0 \mathrm{~m}}$

d

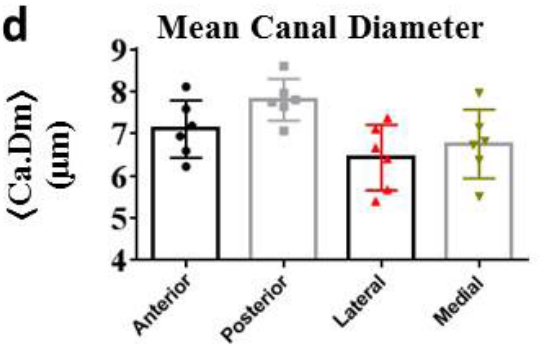

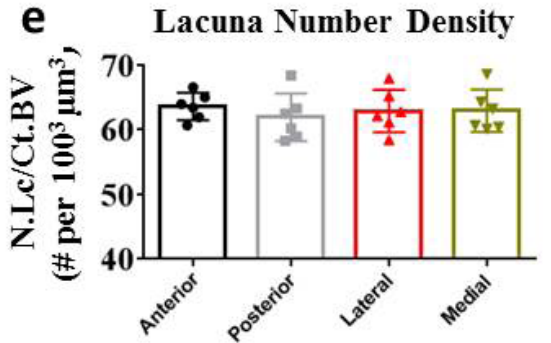

Fig. 9. Vascular and lacunar characterisation upon division of tibiofibular junction into medial, lateral, anterior and posterior quadrants. (a) Intracortical canals in binarised slice and identification of quadrants on tibiofibular junction crosssection. (b) 3D labelling of the canal structures present in the anterior, posterior, lateral and medial regions of a 15-week-old mouse, where different colours highlight disconnected canal structures (see also Table 2). (c) Canal volume density, (d) mean canal diameter and (e) lacuna number density in the 4 regions. Error bars indicate mean values $\pm S D$, $n=6$ biological replicates. ** $p<0.05$. in 10-month-old mice ( $p=0.002$; Fig. $10 \mathbf{b}, \mathbf{c}$ and Table $5)$. No significant age-related changes in mean canal diameter were found in any region ( $p=0.495$; Table $5)$. Lacuna number density was not significantly different among the regions ( $p=0.340$; Table 5) within the two age groups. An age-related reduction in canal volume density was measured in the posterior region, resulting in an increase in mean lacunar distance distribution (Fig. 10d), i.e. in older animals, more lacunae were positioned at longer distances from the blood vessels. Analysis of lacunar distances from bone surfaces showed that osteocytes were embedded significantly further into the mineralised tissue and, thus, more distant from the vasculature in the posterior region for (older) 10-month-old mice $[+14 \%, p=0.002$ for mean lacunar distance distribution (Fig. 10d) and $+15 \%, p=0.004$ for $95^{\text {th }}$ percentile of the lacunar distance distribution (Fig. $4 \mathrm{c}$ and Table 5)]. The opposite effect was observed in the other three regions, where lacunae were located, on average, closer to bone surfaces and blood vessels (Fig. 10d, 4c and Table 5), which appeared to be associated with a thinning of the cortex and, thus, proximity to bone surfaces.

\section{Ageing did not alter vascular canal or osteocyte lacunae occupancy as assessed by histology} Microscopic analysis of calcified bone sections (15week- and 10-month-old tibiae) stained with either pentachrome (Fig. 11a) or Giemsa stains (Fig. 11b) showed the presence of blood vessels within $80-100 \%$ of intracortical canals and of osteocytes within 96$100 \%$ of osteocyte lacunae counted. Upon further analysis, percentage of canal occupancy was not altered with age (Fig. 11c), demonstrating that canals identified by SR-CT in both age groups contained blood vessels. Equally, percentage of occupancy of osteocyte lacunae was not altered with age (Fig. 11d).

\section{Discussion}

Non-invasive high-resolution imaging was used to assess the 3D distribution of intracortical vascular 


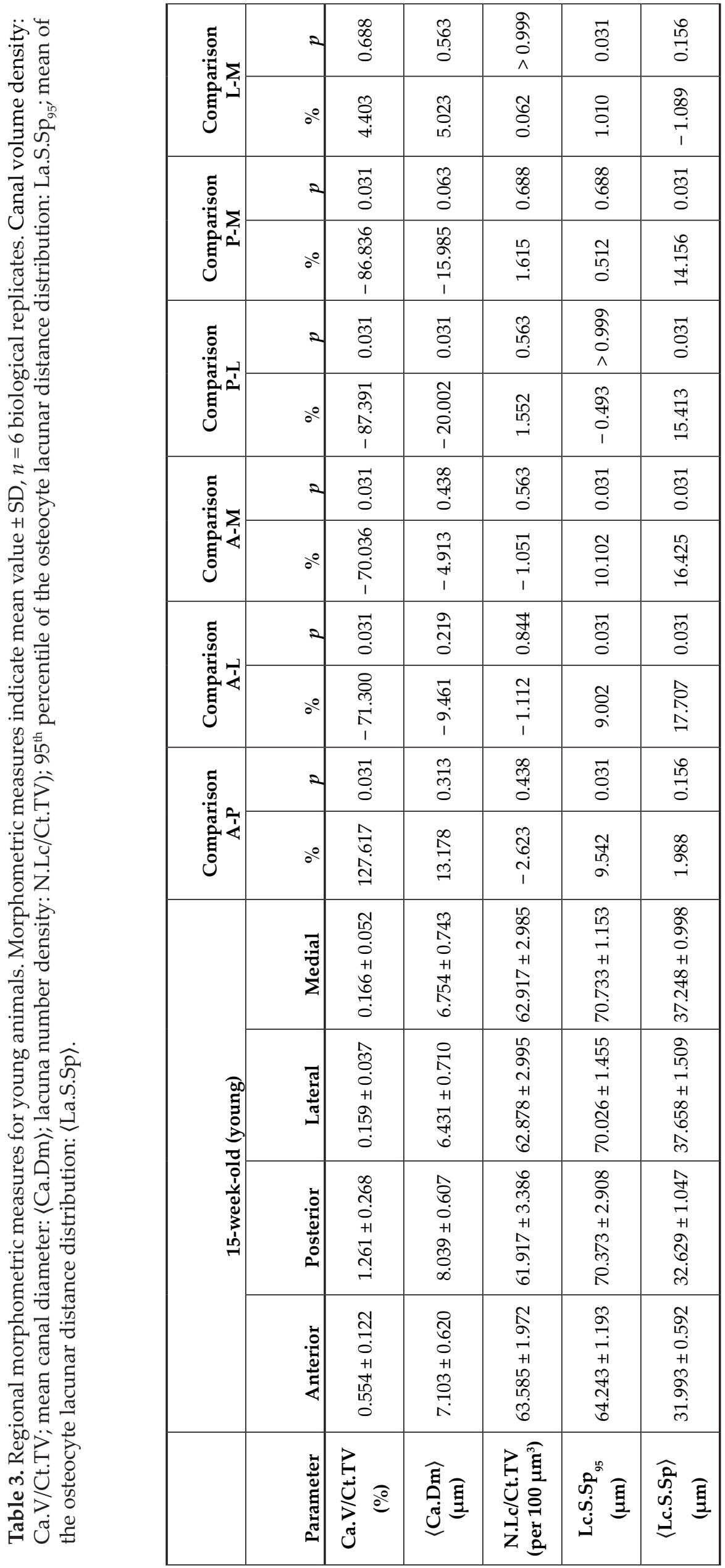


Table 4. Analysis of connectedness of the intracortical canal network in anterior and posterior region of young animals. Morphometric measure indicates mean value $\pm \mathrm{SD}, n=6$ biological replicates.

\begin{tabular}{|c|c|c|c|c|}
\hline Parameter & Anterior & Posterior & Difference (\%) & U test $(p)$ \\
\hline $\begin{array}{c}\text { Canal } \\
\text { connectedness }\end{array}$ & $0.093 \pm 0.011$ & $0.269 \pm 0.053$ & 188.298 & 0.0313 \\
\hline
\end{tabular}

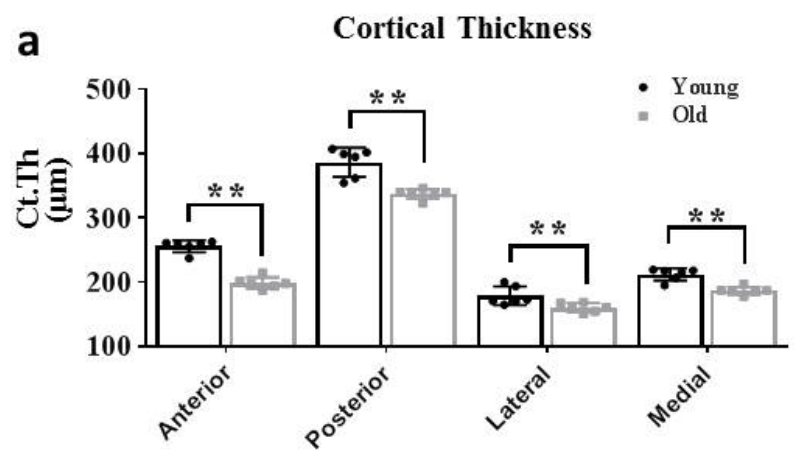

b
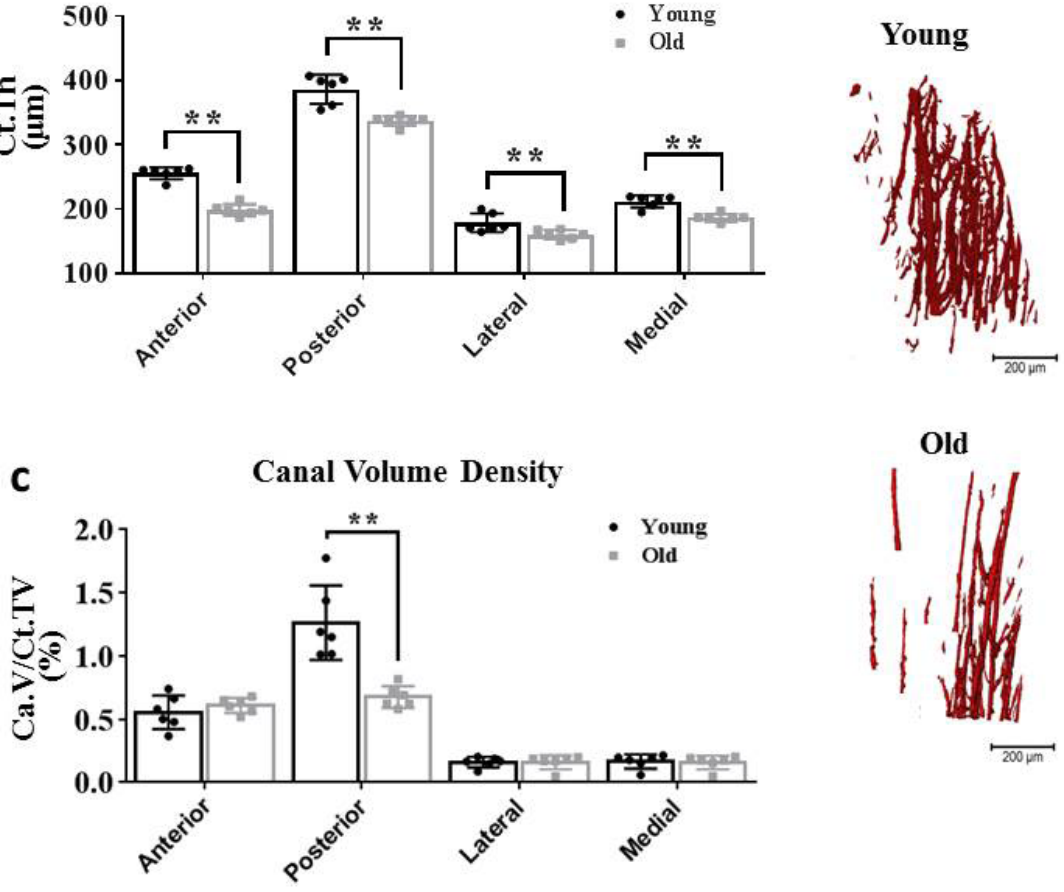

d

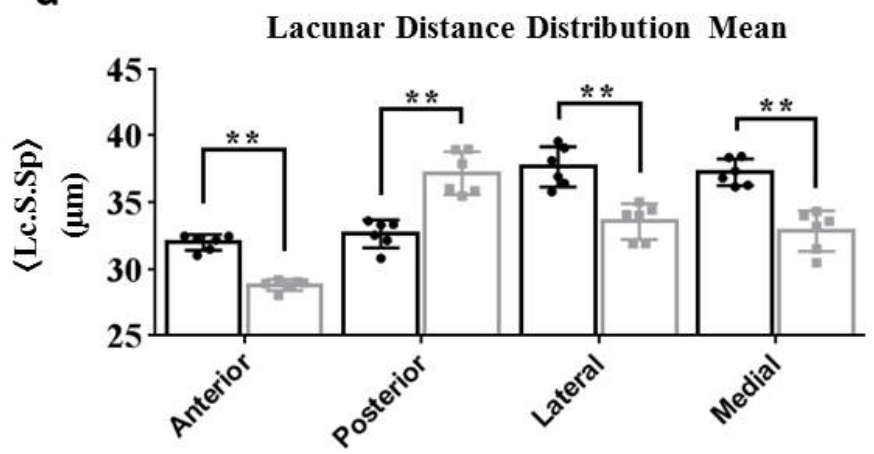

Fig. 10. Effect of age on morphometric measures in cortex divided into quadrants. (a) Evaluation of local cortical thickness for anterior, posterior, lateral and medial regions of young and old mice. (b) 3D renderings of the intracortical vascular canals in posterior region. (c) Canal volume density and (d) mean of lacunar distance distribution to nearest intracortical canal or bone surface for anterior, posterior, lateral and medial regions of young and old mice. Error bars indicate mean value $\pm \mathrm{SD}, n=6$ biological replicates for both age groups. ** $p<0.001$. canals and osteocyte lacunae in the murine tibiofibular junction and to determine site-specific age-related differences in the vascular structures. Specifically, it was shown that 1) anterior and posterior regions of the cortex exhibited higher canal volume density than lateral and medial components; 2) the posterior, but not the anterior region of the junction, exhibited an age-related reduction in vascular canal volume density, associated with a reduction in cortical thickness and bone volume; 3 ) significant age-related differences in cortical canal volume density in the mouse tibiofibular junction were only observed when the cortex was separated into different quadrants.

Regional heterogeneity in the 3D configuration of the intracortical canals (including Haversian canals) of the femoral shaft is identified in humans (Perilli et al., 2015), with intracortical porosity being significantly different in anterior, lateral and medial regions. Moreover, investigations into the porosity of endosteal, intracortical, periosteal outer cortical regions of the femoral diaphysis in rats is reported in a study by Tommasini et al. (2012), who focus on the 


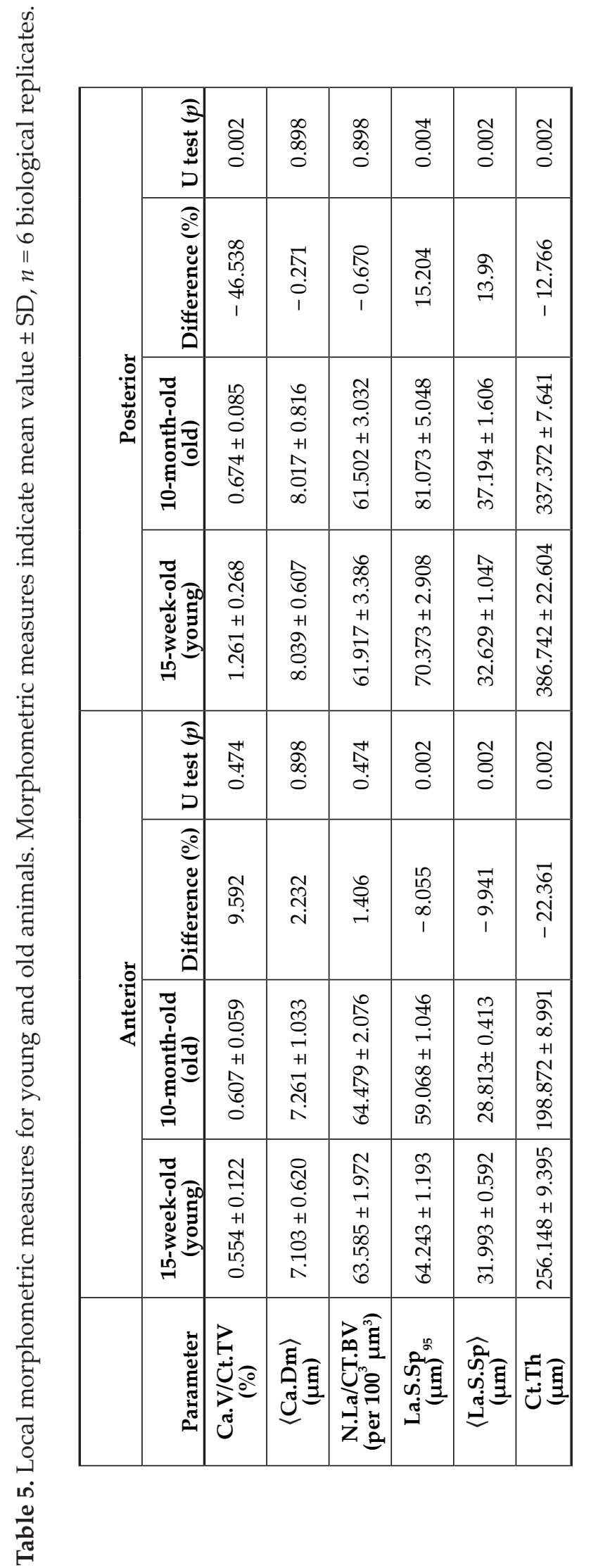

\begin{tabular}{|c|c|c|c|c|c|c|c|}
\hline \multirow{3}{*}{$\begin{array}{l}\mathbb{3} \\
0 \\
z\end{array}$} & 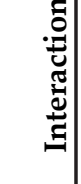 & $\begin{array}{l}\overrightarrow{8} \\
\dot{8} \\
\dot{\circ} \\
v\end{array}$ & $\begin{array}{l}\text { 芯 } \\
\stackrel{0}{0}\end{array}$ & $\begin{array}{l}\text { 命 } \\
\text { مी }\end{array}$ & $\begin{array}{l}\bar{\delta} \\
\dot{8} \\
\dot{0} \\
\mathrm{v}\end{array}$ & $\begin{array}{l}\overrightarrow{8} \\
\dot{0} \\
\dot{0} \\
\mathrm{v}\end{array}$ & $\begin{array}{l}\vec{\Xi} \\
\dot{0} \\
v\end{array}$ \\
\hline & $\begin{array}{l}\text {.0 } \\
\stackrel{0}{0} \\
\approx\end{array}$ & $\begin{array}{l}\vec{\delta} \\
\dot{0} \\
\dot{0} \\
v\end{array}$ & $\begin{array}{l}\overrightarrow{\grave{Q}} \\
\dot{\vec{\theta}}\end{array}$ & $\begin{array}{l}\stackrel{+}{\circ} \\
\stackrel{-}{\circ}\end{array}$ & $\begin{array}{l}\overrightarrow{8} \\
\dot{8} \\
\dot{0} \\
v\end{array}$ & $\begin{array}{l}\bar{\delta} \\
\dot{8} \\
\dot{0} \\
v\end{array}$ & $\begin{array}{l}\vec{\Xi} \\
\vdots \\
\dot{0} \\
v\end{array}$ \\
\hline & 品 & $\begin{array}{l}\vec{\Xi} \\
\dot{0} \\
v\end{array}$ & 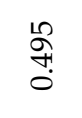 & 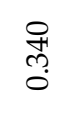 & ڤે సે & $\begin{array}{l}\overrightarrow{8} \\
\dot{0} \\
\dot{0} \\
v\end{array}$ & $\begin{array}{l}\overrightarrow{8} \\
\dot{8} \\
\dot{0} \\
v\end{array}$ \\
\hline \multirow{4}{*}{ 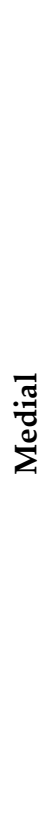 } & 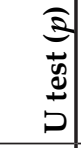 & 茼 & $\begin{array}{l}\text { तै } \\
\stackrel{0}{0}\end{array}$ & $\begin{array}{l}\stackrel{L}{0} \\
\text { ô. } \\
0\end{array}$ & $\begin{array}{l}\text { ¿े } \\
\text { ठ }\end{array}$ & $\begin{array}{l}\tilde{~} \\
\text { oे }\end{array}$ & $\begin{array}{l}\text { ¿े } \\
0 \\
0\end{array}$ \\
\hline & 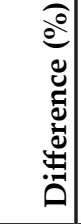 & 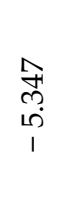 & 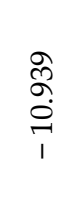 & $\begin{array}{l}\stackrel{\infty}{\infty} \\
\stackrel{+}{+} \\
\text { i } \\
1\end{array}$ & 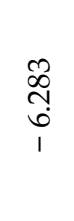 & 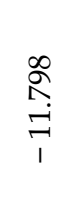 & 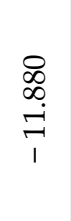 \\
\hline & 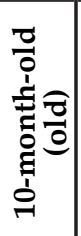 & $\begin{array}{l}\text { 응 } \\
0 \\
0 \\
+1 \\
\stackrel{1}{1} \\
\stackrel{2}{0} \\
0\end{array}$ & $\begin{array}{l}\hat{N} \\
\hat{0} \\
0 \\
+1 \\
0 \\
0 \\
0 \\
0\end{array}$ & 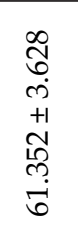 & 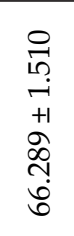 & 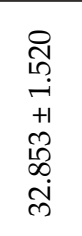 & 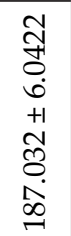 \\
\hline & 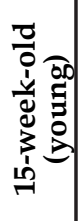 & $\begin{array}{l}\text { గి } \\
0 \\
0 \\
+1 \\
0 \\
0 \\
0 \\
0\end{array}$ & 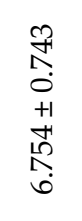 & 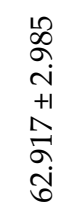 & 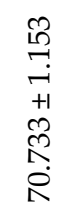 & 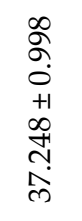 & 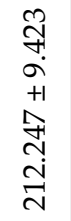 \\
\hline \multirow{4}{*}{ 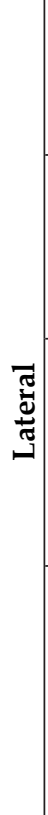 } & 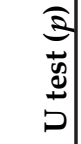 & $\begin{array}{l}\infty \\
\stackrel{\infty}{\infty} \\
\stackrel{0}{0}\end{array}$ & $\begin{array}{c}\infty \\
\stackrel{\infty}{0} \\
0 \\
0\end{array}$ & $\begin{array}{l}\infty \\
\stackrel{\infty}{0} \\
0\end{array}$ & రి & $\begin{array}{l}\tilde{O} \\
\stackrel{0}{0}\end{array}$ & $\stackrel{8}{\circ}$ \\
\hline & 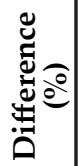 & 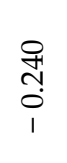 & $\begin{array}{c}0 \\
0 \\
00 \\
0 \\
1\end{array}$ & $\begin{array}{l}\infty \\
\text { î̀ } \\
\text { ஸे } \\
1\end{array}$ & $\begin{array}{c}\text { Î } \\
\text { กี } \\
0 \\
1\end{array}$ & $\begin{array}{l}\vec{\infty} \\
\infty \\
\stackrel{0}{9} \\
\overrightarrow{9} \\
1\end{array}$ & $\begin{array}{l}\stackrel{\infty}{\Im} \\
\stackrel{+}{9} \\
1\end{array}$ \\
\hline & 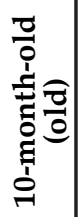 & 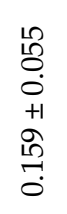 & 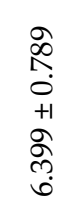 & 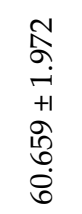 & 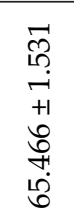 & 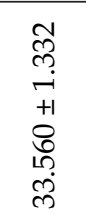 & 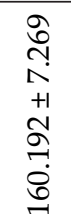 \\
\hline & 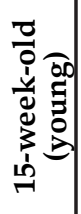 & $\begin{array}{l}\text { مे } \\
0 \\
0 \\
+1 \\
0 \\
0 \\
\stackrel{1}{0} \\
0\end{array}$ & 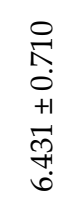 & 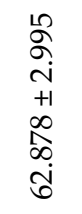 & 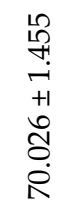 & 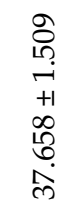 & 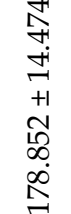 \\
\hline & 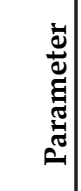 & 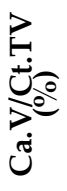 & 它 & 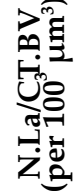 & फ़้ & 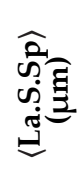 & 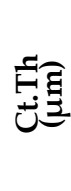 \\
\hline
\end{tabular}


effect of pharmaceutical treatments on intracortical (micro) porosities in untreated ovariectomised (OVX) rats, OVX rats treated with alendronate and OVX rats treated with intermittent parathyroid hormone. The authors show that the effect of the treatment on lacunar morphometric measures and overall percentage of porosity, but not canal volume density, depends on the region (endosteal, intracortical, periosteal). Thomas et al. (2006), using 2D sections of the human femoral midshaft, also report regional diversity in porosity, highlighting that anterior and posterior regions are more porous than lateral and medial.

The observed inferior canal volume density in the lateral and medial quadrants versus the anterior and
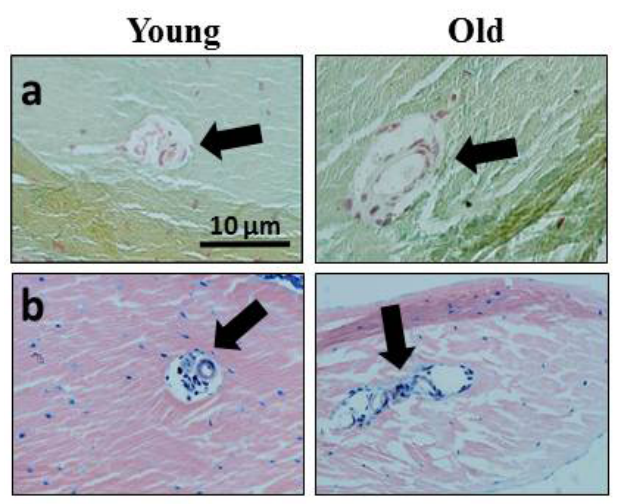

c
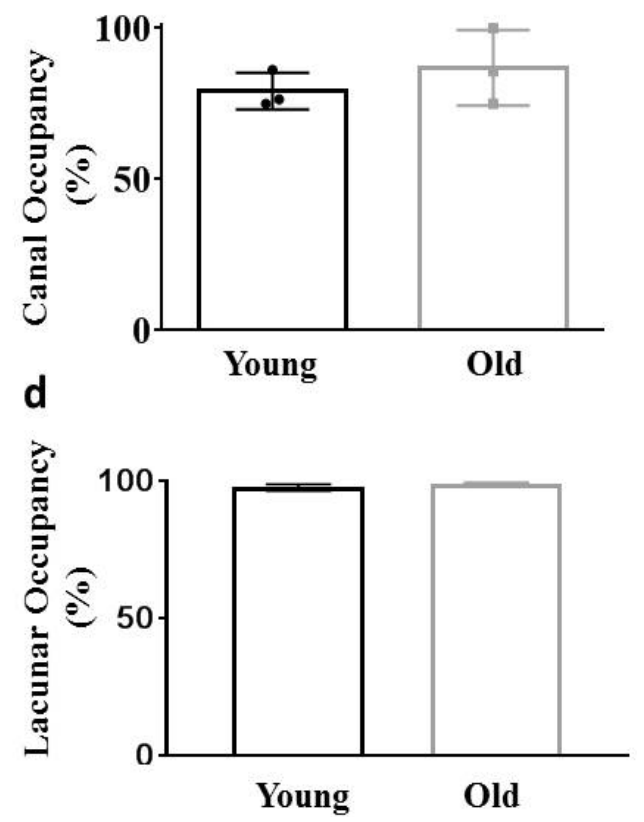

Fig. 11. Histological examination of canal and lacunae occupancy. Arrows highlight blood vessels on histological sections of calcified bone sections from young and old mice using both (a) pentachrome and (b) Giemsa stains. No differences in (c) canal or (d) lacunae occupancy were revealed between old and young mice. Error bars indicate mean value $\pm \mathrm{SD}, n=3$ mice for both age groups. posterior compartments in the murine tibiofibular junction at 15 weeks of age could have a biomechanical explanation. The mechanical strain environment of the murine tibia arises primarily due to bending with peak tensile and compressive strain values located at the anterior and posterior regions, respectively, during locomotion (Prasad et al., 2010). According to the FE results, it appeared that there were inhomogeneous regions of high strain, with larger compressive and tensile strain areas in the medial and lateral regions, respectively, of the anatomical site investigated. The anterior and posterior region showed lower overall strain levels and compressive principal strains appeared to dominate in these regions. How compressive versus tensile strains could directly influence bone vascular canal volume density remained not investigated. However, the results suggested that regions exposed to higher (dynamic) loads and, consequently, sites of more active bone adaptation (i.e. medial and lateral compartments) could negatively regulate the formation of vascular canals, which might ensure optimal mechanical sensitivity adaptation. In contrast, areas exposed to lower strains during load bearing, such as the anterior and posterior regions of the tibiofibular junction, might provide a more stable and favourable environment for the growth and maintenance of blood vessel function. Such an hypothesis provides an interesting avenue for future scrutiny. Recent investigations by Carriero et al. (2014), using a mouse model of osteogenesis imperfecta, combine SR-CT with FE analysis, showing a negative association between the number and branching of canals and the cortical bone's resistance to failure. Although FE analysis between the anterior and posterior regions is not reported in Carriero et al. (2014) study, their data suggest that the anterior region may show a lower risk of bone failure.

A clear structural difference between the human and murine skeleton is that mice lack obvious osteonal or Haversian vascular canals in cortical bone (Cooper et al., 2016). Therefore, the function of the intracortical canals in mice is less clear. It could be suggested that, in mice, there is no physiological requirement for intracortical vessels for osteocyte nutrition, because the cortex is very thin $(<250 \mu \mathrm{m})$, which could explain why Haversian canals are not present. In the current study, it was reported for the first time that vascular canals were present in the posterior region of the tibiofibular cortex and that they were required for osteocyte survival: when they were removed, more than $10 \%$ of all osteocytes were located at a distance of $\approx 120-190 \mu \mathrm{m}$ from the nearest bone surface. Thus, inside the thicker posterior region of the tibia, osteocytes survival and function could be directly affected in the absence of intracortical vessels or following an age-related reduction in canal volume density.

The observations highlighting the reduction in canal volume density in the posterior region and increased osteocyte distances from bone surface/ 
blood vessels suggested an age-related reduction in bone vasculature, specific to this region. As mice do not undergo secondary remodelling, in contrast to ageing in humans (Cooper et al., 2016), it was hypothesised that, at this particular site, the blood vessels might regress with age and the canal spaces be filled with minerals. The composition of such filled canals has never been studied in mice, but future analyses of the intracortical microstructure in the posterior region during ageing, in conjunction with measurements of bone mechanics, could provide new insights into the bone quality at this site.

It is important to highlight that measurements of age-related reduced cortical porosity in the posterior region only accounted for the volume of vascular canals and not for the osteocyte lacunae. In contrast, previous studies report an increase in porosity during ageing in various mouse strains when the cortex is not further separated into specific regions (Courtland et al., 2013; Ferguson et al., 2003; Silbermann et al., 1987; Weiss et al., 1991). It should be noted that the 10 -month-old animals used were younger than the mice used in these previous studies (24-32 months of age) and, hence, severe signs of advanced bone loss were not observed. In addition, early and clear reductions in the intracortical vasculature were observed at this early stage and it is possible that such early vascular alterations might initiate later bone changes, such as hypermineralisation. Importantly, the findings of reductions in vasculature density with ageing were consistent with previous investigations in rodents (Dinenno et al., 1999), confirming that limb blood flow and vascular conductance are reduced in adults. Also, the vasculature contributes to agerelated skeletal pathologies, as circulating VEGF levels in postmenopausal osteoporosis are reduced, (Costa et al., 2009) and associations between VEGF gene polymorphisms that affect VEGF levels and osteoporotic fractures are reported (Chung et al., 2010). Therefore, it was hypothesised that a reduction in VEGF with age could impact the blood vessels within the intracortical canals ahead of any bone change observed.

Differences in vascular canal volume density were described in different regions of cortical bone, which appeared specific to their locality and were suggestive of vascular heterogeneity. Recently, in a landmark publication, Kusumbe et al. (2014) demonstrate that blood vessels associated with trabecular bone are functionally specialised and heterogeneous. Specifically, the authors subdivide bone capillaries into two subtypes, type $\mathrm{H}$ and type L, based on CD31 or endomucin expression, location and interaction with osteogenic cells. Interestingly, while the total number of endothelial cells associated with the bone marrow cavity is not significantly different in juvenile, type $\mathrm{H}$ declines after adolescence in adult and aged mice -which the authors suggest could contribute to the well-known loss of osteogenic capacity and bone mass with ageing (Kusumbe et al., 2014). This alteration in the vasculature is consistent with the observed age-related reduction in vascular canal volume density only in the posterior region. The vascular endothelium is metabolically active and plays a critical role in many physiological processes and it is involved in most, if not all, bone disease states (Eelen et al., 2017). However, a wide bench-tobedside gap exists in endothelial biomedicine and an even wider void in clinically targeting the vasculature for treatment of degenerative bone disease or fracture repair. Site-specific endothelial phenotypes are thought to be initiated and maintained by signals residing in the extracellular environment, which can be biochemical or biomechanical (Ramasamy et al., 2016). Osteoblasts and osteocytes undoubtedly communicate with the endothelium (Clarkin and Gerstenfeld, 2013) and a potential role for them in driving endothelial cell heterogeneity warrants further investigation. Furthermore, recent studies link the role of the vasculature to osteoporosis (Clarkin and Gerstenfeld, 2013; Liu et al., 2012).

However, it is important to note that the differences in vascular canal volume density observed in the posterior region of the murine tibiofibular cortex could be accompanied by regional differences in growth factor secretion within the four quadrants or regions. Results of the present study suggested that environmental differences may exist between cortical regions, including mechanical strain and fluid flow. Such differences could have directly impacted the vascular endothelial cells and contributed to the different blood vessel structures identified and possibly to their behaviour.

An important limitation of this study was the strong focus on the canal network and osteocyte lacunae, which represent the negative imprint of the surrounding mineralised matrix. Soft tissue structures, such as the intracortical vasculature and the osteocytes, typically show a weak image contrast for X-ray absorption-based imaging techniques, such as standard $\mu \mathrm{CT}$. Alternatively, contrast agents for soft tissue visualisation, as reviewed by Pauwels et al. (2013), can be applied for the simultaneous 3D visualisation and quantification of murine bone and bone vasculature. This result can be achieved using $\mu \mathrm{CT}$ (Schneider et al., 2009) or phase contrast imaging methods for (partially) coherent $X$-ray sources, either for soft tissues, such as muscle (Zeller-Plumhoff et al., 2017), or for calcified bone microstructure and intracortical vasculature (Núñez et al., 2017), where $X$-ray phase shifts provide sufficient image contrast for soft tissues.

In summary, lower vascular canal volume density was described in the posterior region of the murine tibiofibular junction accompanied by a thinning of the bone cortex with ageing. Variations in vascular organisation in the four quadrants of the mouse tibiofibular cortex could be linked to habitual biomechanical load-induced strain distribution, but this assumption requires further investigation. Importantly, the posterior region of the tibiofibular junction could also provide a useful experimental site 
to study the role of the vasculature, where vascularspecific mediators play a role in the control of bone thinning during ageing. Degenerative bone diseases, such as osteoporosis, exhibit a reduction in the blood supply and understanding the mechanisms involved in modifying vascular architecture with age could provide a new route for therapeutic intervention to prevent degenerative bone loss and reduce fracture risk.

\section{References}

Alagiakrishnan K, Juby A, Hanley D, Tymchak W, Sclater A (2003) Role of vascular factors in osteoporosis. J Gerontol A Biol Sci Med Sci 58: $362-$ 366.

Bonewald LF (2011) The amazing osteocyte. J Bone Miner Res 26: 229-238.

Bouxsein ML, Boyd SK, Christiansen BA, Guldberg RE, Jepsen KJ, Muller R (2010) Guidelines for assessment of bone microstructure in rodents using micro-computed tomography. J Bone Miner Res 25: 1468-1486.

Brandi ML, Collin-Osdoby P (2006) Vascular biology and the skeleton. J Bone Miner Res 21: 183192.

Britz HM, Jokihaara J, Leppanen O V, Jarvinen T, Cooper DML (2010) 3D visualization and quantification of rat cortical bone porosity using a desktop micro-CT system: a case study in the tibia. J Microsc 240: 32-37.

Britz HM, Jokihaara J, Leppanen OV, Jarvinen TLN, Cooper DML (2012) The effects of immobilization on vascular canal orientation in rat cortical bone. J Anat 220: 67-76.

Brommage R, Liu J, Hansen GM, Kirkpatrick LL, Potter DG, Sands AT, Zambrowicz B, Powell DR, Vogel P (2014) High-throughput screening of mouse gene knockouts identifies established and novel skeletal phenotypes. Bone Res 2: 14034.

Burkhardt R, Kettner G, Bohm W, Schmidmeier M, Schlag R, Frisch B, Mallmann B, Eisenmenger W, Gilg $\mathrm{T}$ (1987) Changes in trabecular bone, hematopoiesis and bone marrow vessels in aplastic anemia, primary osteoporosis, and old age: a comparative histomorphometric study. Bone 8: 157-164.

Burr DB (2010) Cortical bone: a target for fracture prevention?. Lancet 375: 1672-1673.

Campbell GM, Sophocleous A (2014) Quantitative analysis of bone and soft tissue by micro-computed tomography: applications to ex vivo and in vivo studies. Bonekey Rep 3: 564.

Carriero A, Doube M, Vogt M, Busse B, Zustin J, Levchuk A, Schneider P, Muller R, Shefelbine SJ. (2014) Altered lacunar and vascular porosity in osteogenesis imperfecta mouse bone as revealed by synchrotron tomography contributes to bone fragility. Bone 61: 116-124.
Carulli C, Innocenti M, Brandi ML (2013) Bone vascularization in normal and disease conditions. Front Endocrinol (Lausanne) 4: 106.

Chung PY, Beyens G, Boonen S, Papapoulos S, Geusens P, Karperien M, Vanhoenacker F, Verbruggen L, Fransen E, Van Offel J, Goemaere S, Zmierczak HG, Westhovens R, Devogelaer JP, Van Hul W (2010) The majority of the genetic risk for Paget's disease of bone is explained by genetic variants close to the CSF1, OPTN, TM7SF4, and TNFRSF11A genes. Hum Genet 128: 615-626.

Clarkin CE, Emery RJ, Pitsillides AA, WheelerJones CPD (2008) Evaluation of VEGF-mediated signaling in primary human cells reveals a paracrine action for VEGF in osteoblast-mediated crosstalk to endothelial cells. J Cell Physiol 214: 537-544.

Clarkin CE, Gerstenfeld LC (2013) VEGF and bone cell signalling: an essential vessel for communication?. Cell Biochem Funct 31: 1-11.

Cooper DML, Turinsky AL, Sensen CW, Hallgrímsson B (2003) Quantitative 3D analysis of the canal network in cortical bone by micro-computed tomography. Anat Rec 274: 169-179.

Cooper DML, Kawalilak CE, Harrison K, Johnston BD, Johnston JD (2016) Cortical porosity: What is it, why is it important and how can we detect it?. Curr Osteop Rep 14 :187-198.

Cooper DML, Thomas CDL, Clement JG, Turinsky AL, Sensen CW, Hallgrimsson B (2007a) Agedependent change in the 3D structure of cortical porosity at the human femoral midshaft. Bone 40: 957-965.

Cooper D, Turinsky A, Sensen C, Hallgrimsson B (2007b) Effect of voxel size on 3D micro-CT analysis of cortical bone porosity. Calcif Tissue Int 80: 211-219.

Costa N, Paramanathan S, Mac Donald D, Wierzbicki AS, Hampson G (2009) Factors regulating circulating vascular endothelial growth factor (VEGF): association with bone mineral density (BMD) in post-menopausal osteoporosis. Cytokine 46: 376381.

Courtland H-W, Kennedy OD, Wu Y, Gao Y, Sun H, Schaffler MB, Yakar S (2013) Low levels of plasma IGF-1 inhibit intracortical bone remodeling during aging. Age (Dordr) 35: 1691-1703.

Dinenno FA, Jones PP, Seals DR, Tanaka H (1999) Limb blood flow and vascular conductance are reduced with age in healthy humans: relation to elevations in sympathetic nerve activity and declines in oxygen demand. Circulation 100: 164-170.

Dong P, Haupert S, Hesse B, Langer M, Gouttenoire PJ, Bousson V, Peyrin F (2014) 3D osteocyte lacunar morphometric properties and distributions in human femoral cortical bone using synchrotron radiation micro-CT images. Bone 60: 172-185.

Doube M, Kłosowski MM, Arganda-Carreras I, Cordelières FP, Dougherty RP, Jackson JS, Schmid B, Hutchinson JR, Shefelbine SJ (2015) BoneJ: free and extensible bone image analysis in ImageJ. Bone 47: 1076-1079. 
Eelen G, de Zeeuw P, Treps L, Harjes U, Wong BW, Carmeliet P (2017) Endothelial cell metabolism. Physiol Rev 98: 3-58.

Feldkamp LA, Goldstein SA, Parfitt AM, Jesion G, Kleerekoper M (1989) The direct examination of three-dimensional bone architecture in vitro by computed tomography. J Bone Miner Res 4: 3-11.

Ferguson VL, Ayers RA, Bateman TA, Simske SJ (2003) Bone development and age-related bone loss in male C57BL/6J mice. Bone 33: 387-398.

Ferretti JL, Frost HM, Gasser JA, High WB, Jee WS, Jerome C, Mosekilde L, Thompson DD (1995) Perspectives on osteoporosis research: its focus and some insights from a new paradigm. Calcif Tissue Int 57: 399-404.

Frost HM (1963) Bone remodelling dynamics. In: The Henry Ford Hospital Surgical Monographs. Charles C Thomas Company, Springfield, Illinois, USA.

Goggin PM, Zygalakis KC, Oreffo RO, Schneider P (2016) High-resolution 3D imagining of osteocytes and computational modelling in mechanobiology: insights on bone development, ageing, health and disease. Eur Cell Mater 31: 264-295.

Halloran BP, Ferguson VL, Simske SJ, Burghardt A, Venton LL, Majumdar S (2002) Changes in bone structure and mass with advancing age in the male C57BL/6J mouse. J Bone Miner Res 17: 1044-1050.

Ham AW (1952) Some histophysiological problems peculiar to calcified tissues. J Bone Joint Surg Am 24A: 701-728.

Havers C (1691) Osteologia nova, or, some new observations of the bones and the parts belonging to them with the manner of their accretion, and nutrition, communicated to the Royal Society in several discourses (reprinted 1977). Ann Arbor, University Microfilms International, Oxford, UK.

Ham AW (1953) Histology. Philadelphia: JB Lippincott.

Hildebrand T, Rüegsegger P. A new method for the model-independent assessment of thickness in three-dimensional images. J Microsc 185: 67-75.

Holguin N, Brodt MD, Silva MJ (2016) Activation of Wnt signaling by mechanical loading is impaired in the bone of old mice. J Bone Miner Res 31: 2215-2226.

Holzer G, von Skrbensky G, Holzer LA, Pichl W (2009) Hip fractures and the contribution of cortical versus trabecular bone to femoral neck strength. J Bone Miner Res 24: 468-474.

$\mathrm{Hu}$ K, Olsen BR (2016) Osteoblast-derived VEGF regulates osteoblast differentiation and bone formation during bone repair. J Clin Invest 126: 509526.

Jaffe HL (1930) The resorption of bone: A consideration of the underlying processes particularly in pathologic conditions. Arch Surg 20: 355-385.

Kusumbe AP, Ramasamy SK, Adams RH (2014) Coupling of angiogenesis and osteogenesis by a specific vessel subtype in bone. Nature 507: 323-328.

Liu Y, Berendsen AD, Jia S, Lotinun S, Baron R, Ferrara N, Olsen BR (2012) Intracellular VEGF regulates the balance between osteoblast and adipocyte differentiation. J Clin Invest 122: 3101-3113.

Mader KS, Schneider P, Muller R, Stampanoni M (2013) A quantitative framework for the 3D characterization of the osteocyte lacunar system. Bone 57: 142-154.

Maggiano C (2012) Making the mold: a microstructural perspective on bone modeling during growth and mechanical adaptation. Bone Histol Anthropol Perspect: 45-90.

Mazess RB (1990) Fracture risk: a role for compact bone. Calcif Tissue Int 47:191-193.

Núñez JA, Goring A, Hesse E, Thurner PJ, Schneider P, Clarkin CE (20170. Simultaneous visualisation of calcified bone microstructure and intracortical vasculature using synchrotron X-ray phase contrast-enhanced tomography. Scientific Reports 7: 13289.

Palacio-Mancheno PE, Larriera AI, Doty SB, Cardoso L, Fritton SP (2014) 3D assessment of cortical bone porosity and tissue mineral density using highresolution $\mu \mathrm{cT}$ : effects of resolution and threshold method. J Bone Miner Res 29: 142-150.

Parfitt AM (2000) The mechanism of coupling: a role for the vasculature. Bone 26: 319-323.

Parfitt AM, Drezner MK, Glorieux FH, Kanis JA, Malluche H, Meunier PJ, Ott SM, Recker RR (1987) Bone histomorphometry: standardization of nomenclature, symbols, and units. Report of the ASBMR Histomorphometry Nomenclature Committee. J Bone Miner Res 2: 595-610.

Pauwels E, Van Loo D, Cornillie P, Brabant L, Van Hoorebeke L (2013). An exploratory study of contrast agents for soft tissue visualization by means of high resolution X-ray computed tomography imagining. J Microsc 250: 21-31.

Perilli E, Bala Y, Zebaze R, Reynolds KJ, Seeman E (2015) Regional heterogeneity in the configuration of the intracortical canals of the femoral shaft. Calcif Tissue Int 97: 327-335.

Prasad J, Wiater BP, Nork SE, Bain SD, Gross TS (2010) Characterizing gait induced normal strains in a murine tibia cortical bone defect model. J Biomech 43: 2765-2770.

Ramasamy KS, Kusumbe AP, Schiller M, Zeuschner D, Bixel MG, Milia C, Gamrekelashvili J, Limbourg A, Medvinsky A, Massimo M, Santoro MM, Limbourg FP, Adams RH (2016) Blood flow controls bone vascular function and osteogenesis. Nat Commun 7: 13601.

Razi H, Birkhold AI, Zaslansky P, Weinkamer R, Duda GN, Willie BM, Checa S (2015) Skeletal maturity leads to a reduction in the strain magnitudes induced within the bone: a murine tibia study. Acta Biomater 13: 301-310.

Reeve J, Arlot M, Wootton R, Edouard C, Tellez M, Hesp R, Green JR, Meunier PJ (1988) Skeletal blood flow, iliac histomorphometry, and strontium kinetics in osteoporosis: a relationship between blood flow and corrected apposition rate. J Clin Endocrinol Metab 66: 1124-1131. 
Schneider P, Krucker T, Meyer E, UlmannSchuler A, Weber B, Stampanoni M, Müller R (2009) Simultaneous 3D visualization and quantification of murine bone and bone vasculature using microcomputed tomography and vascular replica. Microsc Res Tech 72: 690-701.

Schneider P, Stauber M, Voide R, Stampanoni M, Donahue LR (2007) Ultrastructural Properties in cortical bone vary greatly in two inbred strains of mice as assessed by synchrotron light based microand nano-CT. J Bone Miner Res 22: 1557-1570.

Schneider CA, Rasband WS, Eliceiri KW (2012) NIH Image to ImageJ: 25 years of image analysis. Nature Methods 9: 671-675.

Schneider P, Voide R, Stampanoni M, Donahue LR, Müller R (2013) The importance of the intracortical canal network for murine bone mechanics. Bone 53: 120-128.

Silbermann M, Weiss A, Reznick AZ, Eilam Y, Szydel N, Gershon D (1987) Age-related trend for osteopenia in femurs of female C57BL/6 mice. Compr Gerontol A 1: 45-51.

Somerville JM, Aspden RM, Armour KE, Armour KJ, Reid DM (2004) Growth of C57BL/6 mice and the material and mechanical properties of cortical bone from the tibia. Calcif Tissue Int 74: 469-475.

Thomas CDL, Feik SA, Clement JG (2006) Increase in pore area, and not pore density, is the main determinant in the development of porosity in human cortical bone. J Anat 209: 219-230.

Thurner PJ, Chen CG, Ionova-Martin S, Sun L, Harman A, Porter A, Ager JW, Ritchie RO, Alliston T (2010) Osteopontin deficiency increases bone fragility but preserves bone mass. Bone 46: 1564-1573.

Tommasini SM, Trinward A, Acerbo AS, de Carlo F, Miller LM, Judex S (2012) Changes in intracortical microporosities induced by pharmaceutical treatment of osteoporosis as detected by high resolution microCT. Bone 50: 596-604.

Warner SE, Sanford DA, Becker BA, Bain SD, Srinivasan S, Gross TS (2006) Botox induced muscle paralysis rapidly degrades bone. Bone 38: 257-264.

Weibel ER (1989) Measuring through the microscope: development an devolution of stereological methods. J Microsc 155: 393-403.

Weiss A, Arbell I, Steinhagen-Thiessen E, Silbermann M (1991) Structural changes in aging bone: osteopenia in the proximal femurs of female mice. Bone 12: 165-172.
You LD, Weinbaum S, Cowin SC, Schaffler MB (2004). Ultrastructure of the osteocyte process and its pericellular matrix. Anat Rec A Discov Mol Cell Evol Biol 278: 505-153.

Zebaze R, Seeman E (2015) Cortical bone: a challenging geography. J Bone Miner Res 30: 24-29.

Zeller-Plumhoff B, Roose T, Katsamenis OL, Mavrogordato MN, Torrens C, Schneider P, Clough GF (2017). Phase contrast synchrotron radiation computed tomography of muscle spindles in the mouse soleus muscle. J Anat 230: 859-865.

\section{Discussion with Reviewer}

Steven Tommasini: Were there any regional differences in osteocyte lacunae size and shape? Were there any differences in these parameters in relation to the distance from the bone or canal surfaces?

Authors: Although the osteocyte lacunae shape and orientation/alignment would be interesting to study, it was not the focus of this study, as the working hypothesis was that the intracortical vasculature was reduced with age. Moreover, the calculations of the osteocyte lacunae shape and orientation/alignment are prone to small changes in voxel size, as shown in Mader et al. (2013). Instead, the 3D distribution of vascular structures and osteocyte lacunae was derived to interrogate their spatial relationships.

Steven Tommasini: Was lacunar volume measured? Whether or not there were changes in the number of lacunae, the size of the lacunae may have changed with age, which may affect bone's response to mechanical loading.

Authors: Although interesting, lacunae size or volume were not the focus of the current work; however, osteocyte density (per $100 \mu \mathrm{m}^{3}$ ) was presented and the 3D distribution of vascular structures and osteocyte lacunae was uniquely derived to interrogate their spatial relationships, as presented in this manuscript.

Editor's note: The Scientific Editor responsible for this paper was Jürg Gasser. 